\title{
Formaldehyde total column densities over Mexico City: comparison between multi-axis differential optical absorption spectroscopy and solar-absorption Fourier transform infrared measurements
}

\author{
Claudia Rivera Cárdenas ${ }^{1}$, Cesar Guarín ${ }^{1,2}$, Wolfgang Stremme ${ }^{1}$, Martina M. Friedrich ${ }^{1,3}$, Alejandro Bezanilla ${ }^{1}$, \\ Diana Rivera Ramos ${ }^{1}$, Cristina A. Mendoza-Rodríguez ${ }^{1}$, Michel Grutter ${ }^{1}$, Thomas Blumenstock ${ }^{4}$, and Frank Hase ${ }^{4}$ \\ ${ }^{1}$ Centro de Ciencias de la Atmósfera, Universidad Nacional Autónoma de México, Mexico City, Mexico \\ ${ }^{2}$ Departamento de Física, Universidad Autónoma Metropolitana, Mexico City, Mexico \\ ${ }^{3}$ Royal Belgian Institute for Space Aeronomy (BIRA-IASB), Brussels, 1180, Belgium \\ ${ }^{4}$ Institute of Meteorology and Climate Research, Karlsruhe Institute of Technology, Karlsruhe, Germany
}

Correspondence: Claudia Rivera Cárdenas (claudia.rivera@atmosfera.unam.mx)

Received: 27 May 2020 - Discussion started: 1 September 2020

Revised: 25 November 2020 - Accepted: 9 December 2020 - Published: 28 January 2021

\begin{abstract}
Formaldehyde (HCHO) total column densities over the Mexico City metropolitan area (MCMA) were retrieved using two independent measurement techniques: multi-axis differential optical absorption spectroscopy (MAX-DOAS) and Fourier transform infrared (FTIR) spectroscopy. For the MAX-DOAS measurements, the software QDOAS was used to calculate differential slant column densities (dSCDs) from the measured spectra and subsequently the Mexican MAX-DOAS fit (MMF) retrieval code to convert from dSCDs to vertical column densities (VCDs). The direct solar-absorption spectra measured with FTIR were analyzed using the PROFFIT (PROFile FIT) retrieval code. Typically the MAX-DOAS instrument reports higher VCDs than those measured with FTIR, in part due to differences found in the ground-level sensitivities as revealed from the retrieval diagnostics from both instruments, as the FTIR and the MAX-DOAS information do not refer exactly to the same altitudes of the atmosphere. Three MAX-DOAS datasets using measurements conducted towards the east, west or both sides of the measurement plane were evaluated with respect to the FTIR results. The retrieved MAX-DOAS HCHO VCDs where $6 \%, 8 \%$ and $28 \%$ larger than the FTIR measurements which, supported with satellite data, indicates a large horizontal inhomogeneity in the $\mathrm{HCHO}$ abundances. The temporal change in the vertical distribution of this pollutant, guided by the evolution of the mixing-layer height, af-
\end{abstract}

fects the comparison of the two retrievals with different sensitivities (total column averaging kernels). In addition to the reported seasonal and diurnal variability of HCHO columns within the urban site, background data from measurements at a high-altitude station, located only $60 \mathrm{~km}$ away, are presented.

\section{Introduction}

Megacities are in constant evolution, exhibiting continuous changes in territorial extension, population size and spatial redistribution, as well as in the types of socio-economic activities performed every day. In many cases the spatial growth is uneven, resulting in areas of the city being more prone to emissions or accumulation of pollutants due to chemical transformations or transport patterns influenced by meteorological conditions. For the specific case of the Mexico City metropolitan area (MCMA), the urban sprawl observed over the years has been topographically influenced, causing redensification processes due to the space-limited valley location of the MCMA (Taubenböck et al., 2012). The associated natural emissions in and around the MCMA (central Mexican matorral - shrubland - and Trans-Mexican Volcanic Belt pine-oak forests), along with the daily activities conducted by the MCMA population of nearly 22 million inhabitants for 
the base year of 2018, according to the Demographic Statistics Database of the United Nations Statistics Division (UN, 2019), are considered as the main drivers of the enhancement of formaldehyde in the atmospheric column over the MCMA.

Formaldehyde (HCHO), a hazardous pollutant present mostly in the lower troposphere, is the most abundant carbonyl compound found in urban areas such as Mexico City. Due to its short lifetime of only a few hours, the quantitative determination of this gas gives an idea of the distribution of its sources (Stavrakou et al., 2009). It can be directly emitted by several sources including automobile exhaust, natural gas combustion, biomass burning, building materials, personal care and cleaning products, among many others. It can likewise be emitted directly by vegetation, although in low concentrations (Kesselmeier et al., 1997). Formaldehyde is mainly formed in the air from the oxidation and degradation of methane and many non-methane volatile organic compounds (NMVOCs), both of biogenic and anthropogenic origin (Finlayson-Pitts and Pitts, 2000; Solal et al., 2008), and is a radical source involved in urban tropospheric chemistry and ozone formation (Lei et al., 2009).

There are two main reactions that $\mathrm{HCHO}$ undergoes in the atmosphere, photolysis and reaction with $\mathrm{OH}$ (Seinfeld and Pandis, 2012), leading to the formation of carbon monoxide, which in turn produces tropospheric ozone.

$$
\begin{aligned}
\mathrm{HCHO}+h v & \rightarrow \mathrm{H} \cdot+\mathrm{HCO} \\
& \rightarrow \mathrm{H}_{2}+\mathrm{CO} \\
\mathrm{HCHO}+\mathrm{OH} \bullet & \rightarrow \mathrm{HCO}+\mathrm{H}_{2} \mathrm{O}
\end{aligned}
$$

Deriving the global burden and emissions of many NMVOCs is a real challenge from the limited observations available; however, satellite HCHO observations can constrain their emissions in global chemistry transport models and thus provide a better understanding of their spatial distributions and temporal variability.

Remote sensing techniques are a useful complement in the quantification of gases by measuring the total atmospheric column amount along a line of sight. Spectrometers installed on board satellites, aircraft, balloons, vehicles or groundbased stations have the capacity to determine the atmospheric composition of gases and particles by observing their characteristic interaction with the radiation field. A common technique deployed from the ground is solar-absorption Fourier transform infrared (FTIR) spectroscopy, capable of quantifying vertical column densities and profiles of a wide range of gases (Hase et al., 2004; Stremme et al., 2009; Bezanilla et al., 2014). A comprehensive study by Vigouroux et al. (2018) was carried out for HCHO to harmonize the retrieval settings of 20 ground-based FTIR instruments contributing to the Network for the Detection of Atmospheric Composition Change (NDACC). HCHO can also be measured with the differential optical absorption spectroscopy (DOAS) technique (Platt and Stutz, 2008). The retrieved HCHO slant columns measured with nine DOAS instruments in the multi-axis configurations (MAX-DOAS) were intercompared in the CINDI (Cabauw Intercomparison campaign of Nitrogen Dioxide measuring Instruments) field campaign and presented consistent results (Pinardi et al., 2013). During the CINDI-2 campaign, considerable differences on the differential slant column densities retrieved from measurements conducted by different instruments were identified (Kreher et al., 2020). The advantage of the MAX-DOAS technique in comparison to the zenith-sky DOAS approach is that vertical column densities can be retrieved with some information on the vertical distribution in the lower troposphere (Platt and Stutz, 2008).

Some comparisons between FTIR and MAX-DOAS instruments have been done in the past. Surface HCHO was measured with two spectroscopic techniques by Grutter et al. (2005) in the Mexico City downtown area during 2003, reporting monthly averages that ranged between 12.7 and $23.9 \mathrm{ppm}$. In that study, the products derived from open-path FTIR and long-path DOAS agreed within $15 \%$. Vigouroux et al. (2009) found a good agreement in HCHO columns retrieved from solar-absorption FTIR and MAX-DOAS measurements during campaigns performed in 2004 and 2007 on Reunion Island. The ground-based observations were also compared with the SCIAMACHY (Scanning Imaging Absorption Spectrometer for Atmospheric Chartography) satellite product and from results of a chemical transport model. Franco et al. (2015) retrieved vertical profiles from MAX-DOAS and FTIR at the Jungfraujoch station, which were subsequently compared to two chemical transport models (GEOS-Chem - Goddard Earth Observing System - and IMAGES v2 - Intermediate Model of Annual and Global Evolution of Species), concluding that both measurement techniques (FTIR and MAX-DOAS) can be considered as providing complementary information for the retrieval of HCHO above the Jungfraujoch station. Tirpitz et al. (2021) found very good agreement of MAX-DOASretrieved vertical column densities (VCDs) compared to direct-sun DOAS (an average root-mean-square difference of $1.4 \times 10^{15}$ molec. $\mathrm{cm}^{-2}$ ) as found during CINDI-2. Another study by Garcia et al. (2006) aimed at evaluating the relative primary (directly emitted) to secondary (photochemically produced) contributions to ambient $\mathrm{HCHO}$ concentrations in Mexico City. By using a statistical analysis and carbon monoxide and glyoxal as gas-phase tracers of primary and secondary $\mathrm{HCHO}$, respectively, they found that during daytime the photochemically produced $\mathrm{HCHO}$ may account for up to $80 \%$, while during the night and before sunrise the primary sources, such as vehicle emissions, dominate the HCHO concentrations at the surface. In a study conducted by Lei et al. (2009), the impact of primary HCHO on pollution in Mexico City was analyzed. The authors indicate that $\mathrm{HCHO}$ emitted by primary sources dominates the concentration of this carbonyl both in the morning and at night, and HCHO decreases by approximately $1 / 3$ in the afternoon. 
In this study, we use a time series of more than 7 years to perform an unprecedented comparison (in terms of length and location) of the $\mathrm{HCHO}$ total vertical column amount measured with two independent techniques. Retrieval diagnostics from both the MAX-DOAS and FTIR results are used to characterize the difference in both measurement techniques and to improve the agreement and correlation between coincident data pairs (Sect. 3.3). The seasonal and diurnal variability of HCHO columns is reported from a measurement site in the Mexico City urban area, as well as from a remote site in a high-altitude station located only $60 \mathrm{~km}$ away (Sect. 3.1). Together with space-based observations (Sect. 3.2), these results do not only serve to explain the local conditions in which this pollutant is emitted, produced and transported within the Mexico City metropolitan area (MCMA) but will also provide confidence in the validation activities of model results as well as of the current and future satellite missions.

\section{Methodology}

In this section we describe the two independent measurement techniques, based on FTIR spectroscopy and MAX-DOAS, used to retrieve $\mathrm{HCHO}$ vertical column densities over two measurement sites. One of the sites is in the south of the MCMA, at the Universidad Nacional Autónoma de México (UNAM) campus - National Autonomous University of Mexico - on the roof of the Centro de Ciencias de la Atmósfera (CCA-UNAM, lat 19.32, long -99.17, 2280 m a.s.l.) - Center for Atmospheric Sciences. The other site is the Altzomoni Atmospheric Observatory, a high-altitude research facility located in the Iztaccíhuatl-Popocatépetl National Park, $60 \mathrm{~km}$ southeast of Mexico City (lat 19.12, long $-98.66,3985 \mathrm{~m}$ a.s.1.). Both the UNAM and Altzomoni stations are part of the Red Universitaria de Observatorios Atmosféricos (RUOA) national monitoring network - University Network of Atmospheric Observatories - and the Altzomoni station is also part of the NDACC international network.

\subsection{Solar-absorption FTIR measurements}

The UNAM station is equipped with a Fourier transform infrared spectrometer (FTIR) from Bruker Optics (model Vertex 80) that measures solar-absorption spectra at different spectral regions with mercury-cadmium-telluride (MCT) and indium-gallium-arsenide (InGaAs) detectors and five band-pass filters placed on a rotating wheel. The interferometer has a maximal optical-path difference of $12 \mathrm{~cm}$ and continually records spectra at $0.075 \mathrm{~cm}^{-1}$ resolution. The light from the sun is followed with a custom-built solar tracker mounted inside an astronomical dome that is automated so that it can measure from sunrise to nightfall, as long as there are no clouds, and ensures measurements are conducted with a $7 \mathrm{mrad}$ field of view (smaller than the solar disk). The solar tracker has been continuously improved over the years and uses, in its current version, a camera mounted behind a beam splitter in the optical bench that is used as feedback to optimize the pointing to the sun (Bezanilla et al., 2014).

At the Altzomoni remote site, a high-resolution FTIR (Bruker Optics, IFS120/5 HR) is operated remotely with a microwave antenna that allows us to have communication with the station. This instrument allows a maximal opticalpath difference of $257 \mathrm{~cm}$, recording spectra typically at $0.005 \mathrm{~cm}^{-1}$ resolution, and its solar tracker uses an astronomical telescope mount that is controlled by the Camtracker software (Gisi et al., 2011; Gisi, 2012). Further details about the instrumental setup are provided elsewhere (Baylon et al., 2017; Plaza-Medina et al., 2017; Taquet et al., 2019).

Vertical column densities (VCDs) are retrieved from solar-absorption FTIR spectra in four spectral microwindows in the region between 2763 and $2782 \mathrm{~cm}^{-1}$, using the spectroscopic line-data compilation AMT16 (Toon et al., 2016), available at http://mark4sun.jpl.nasa.gov/toon/linelist/ linelist.html (last access: 20 January 2020); a Tikhonov L1 constraint; and an a priori volume mixing ratio (VMR) profile taken as a 41-year mean (1980-2020) from the Whole Atmosphere Community Climate Model (WACCAM, version 4) run over the particular measurement sites. Although this a priori profile would correspond to the background HCHO concentration and not to the polluted conditions in Mexico City, this will not affect the resulting profile, as a Tikhonov L1 constraint is used and just the relative shape of the vertical a priori profile is relevant for the constraint. The retrieval strategy and error analysis follow the instructions described by Vigouroux et al. (2018). The data are processed using the retrieval code PROFFIT9 (PROFile FIT; Hase et al., 2004), and the random errors at UNAM and Altzomoni are estimated to be around $5 \%\left(1.1 \times 10^{15}\right.$ molec. $\left.\mathrm{cm}^{-2}\right)$ and $10 \%\left(0.2 \times 10^{15}\right.$ molec. $\left.\mathrm{cm}^{-2}\right)$ of the corresponding mean columns $\left(22.1 \times 10^{15}\right.$ molec. $\mathrm{cm}^{-2}, 2.18 \times 10^{15}$ molec. $\left.\mathrm{cm}^{-2}\right)$ (Vigouroux et al., 2018).

\subsection{The MAX-DOAS measurements}

A MAX-DOAS instrument, designed and built by the Spectroscopy and Remote Sensing Group at CCA-UNAM, was used to conduct sky measurements in the UV-Vis (ultraviolet-visible) region of the electromagnetic spectrum. The MAX-DOAS instrument, which has been collecting data since 2013, is installed on the roof of CCA-UNAM (same location as the FTIR-Vertex instrument) and forms part of a small network (Arellano et al., 2016) of MAX-DOAS instruments that covers part of the MCMA.

The MAX-DOAS has a theoretical field of view of $0.31^{\circ}$ (Arellano et al., 2016) and performs measurement sequences with a telescope's azimuth angle of $85^{\circ}$ with respect to the north. Each elevation scan of the MAX-DOAS measurements starts with a zenith measurement. This is followed by a 
Table 1. DOAS analysis settings for HCHO slant column density retrieval.

\begin{tabular}{ll}
\hline Parameter & Specification \\
\hline Fitting interval & 324.6 to $359 \mathrm{~nm}$ \\
\hline Cross sections & \\
\hline $\mathrm{HCHO}$ & Meller and Moortgat (2000) at 298 K \\
\hline $\mathrm{O}_{3}$ & Serdyuchenko et al. (2014) at 223 and 243 K \\
\hline $\mathrm{NO}_{2}$ & Vandaele et al. (1998) at 298 K \\
\hline $\mathrm{BrO}$ & Fleischmann et al. (2004) at 223 K \\
\hline $\mathrm{O}_{4}$ & Thalman and Volkamer (2013) \\
\hline $\mathrm{Ring}$ spectrum & $\begin{array}{l}\text { Calculated with QDOAS according to } \\
\text { Chance and Spurr (1997) and normalized } \\
\text { as in Wagner et al. (2009) }\end{array}$ \\
\hline
\end{tabular}

number of measurements towards different elevation angles, starting at low angles, all towards the same azimuthal direction. Approaching the zenith direction, the scan is continued in reverse order for the elevation angles towards the opposite azimuthal direction, from large elevation angles towards small elevation angles. The measurement sequence, as specified in Friedrich et al. (2019), is $90^{\circ}$ zenith, 0, 2, 6, 13, 23, $36,50,65,82^{\circ} \mathrm{W}, 82,65,50,36,23,13,6,2$ and $0^{\circ} \mathrm{E}$. At the end of each scan, a dark spectrum is taken (closed shutter). With this setup, a complete scan takes about $7 \mathrm{~min}$. The dark spectrum is subtracted from all other spectra measured during the sequence (including the zenith spectrum). A detailed instrument description and measurement strategy can be found in Arellano et al. (2016) and Friedrich et al. (2019).

Before conducting retrievals, spectra are filtered with the objective to remove all spectra either with light conditions that are too low (10\% or less of the maximum possible intensity level) or saturated spectra in the retrieval region. Differential slant column densities (dSCDs) are retrieved from the collected spectra at different elevation angles, following a DOAS approach using the QDOAS software developed at the Belgian Institute for Space Aeronomy (Danckaert et al., 2017). A wavelength calibration was conducted in QDOAS by applying a nonlinear least-squares fit to a solar atlas (Chance and Kurucz, 2010). HCHO was retrieved in the 324.6 to $359 \mathrm{~nm}$ wavelength range, a polynomial order 5 was used along with an offset order 1 (linear offset) (Hendrick et al., 2016; Gaia Pinardi, personal communication, 2017). Specific details about the used cross sections are provided in Table 1. Cross sections were convolved with the instrumental slit function and a wavelength calibration file created using a mercury lamp. $\mathrm{O}_{4}$ was retrieved in the 336 to $390 \mathrm{~nm}$ wavelength range, following settings described in Friedrich et al. (2019).
HCHO VCDs were retrieved using the Mexican MAXDOAS fit (MMF) code (Friedrich et al., 2019). MMF uses HCHO dSCDs and converts them into VCDs in a two-step process for each scan: first, the $\mathrm{O}_{4}$ slant column density information is used to retrieve an aerosol profile. In the second step, the retrieved aerosol profile information is used together with the HCHO dSCDs to retrieve the trace gas profile. Both parts follow a procedure that consists of a forward model and an inversion algorithm. A constrained least-squares fit is used in both steps, but the aerosol retrieval uses Tikhonov regularization, and the trace gas retrieval uses optimal estimation. The forward model uses the radiative transfer code VLIDORT v2.7 (Vector LInearized Discrete Ordinate Radiative Transfer; Spurr et al., 2001; Spurr, 2006, 2013). The inputs to VLIDORT are calculated using temperature and pressure information from daily radiosonde measurements and aerosol single-scattering optical depths and asymmetry factors from the AERONET (Aerosol Robotic Network) database for Mexico City.

To run MMF retrievals, the absorption cross section was taken at a wavelength in between the range of the wavelength interval used for the QDOAS retrieval: for $\mathrm{O}_{4}$ retrieval it was $360 \mathrm{~nm}$ and for HCHO it was $338 \mathrm{~nm}$. For aerosol, the a priori profile shape was taken from 1 year of ceilometer data which was averaged each hour. The a priori aerosol data for total optical depth were time-interpolated from the colocated AERONET station in Mexico City. For HCHO retrieval, a single a priori profile and covariance matrix taken from the chemical transport model WRF-Chem (Weather Research and Forecasting - WRF - model coupled with Chemistry) was used. The surface albedo used in this study was set to 0.07. For the retrieved HCHO MAX-DOAS VCDs, the calculated noise error of the mean column is $5.8 \%$ while the systematic error due to uncertainty in the spectroscopy is $2.2 \%$.

Three different versions of HCHO VCDs were retrieved using the MMF code: V1 retrieved VCDs from MAX-DOAS measurements conducted towards the east (telescope's azimuth angle of $85^{\circ}$ with respect to the north); V2 retrieved VCDs from MAX-DOAS measurements conducted towards the west (telescope's azimuth angle of $265^{\circ}$ with respect to the north); and V3 retrieved VCDs from MAX-DOAS measurements conducted towards both sides of the scanning plane. To simplify terminology, for the remainder of the paper, version V1 will be referred as "east"; version V2 will be referred as "west"; and version V3 will be referred as "both".

For V1, V2 and V3 the same a priori is used both for the trace gas and for the aerosol. For V3, the "scan" is simply treated as consisting of two different azimuth directions. The $\mathrm{V} 1, \mathrm{~V} 2$ and $\mathrm{V} 3$ retrievals are performed independent of each other and differ in the definition of a "scan", where V3 contains all pointing directions from V1 and V2 together. A single vertical profile is retrieved in both directions for V3, so assuming horizontal homogeneity. This assumption clearly is not fulfilled; however, it is also not fulfilled in a single 
viewing direction, since the effective light path is around 5$20 \mathrm{~km}$. As pointed out in the paper, the advantage of using both directions is a higher information content, while the disadvantage is a more rigorous breakdown of the homogeneity assumption.

\section{Results}

\subsection{Diurnal and seasonal variability of $\mathrm{HCHO}$ in Mexico City}

A large dataset of measurements taken at the UNAM site between January 2013 and May 2020 allowed us to study the diurnal and seasonal variability of HCHO. Figure 1 shows the time series of HCHO VCD hourly means from the MAXDOAS (V1, V2 and V3) and from FTIR instruments located at this urban site. Additionally, HCHO VCDs from a highresolution FTIR instrument were measured from the remote site at Altzomoni, providing relevant information about the variability of the background concentrations (see Sect. 3.4). One can see that both instruments located at UNAM report values in the same order of magnitude; however, higher values in MAX-DOAS measurements than the FTIR instrument are apparent. This is in part attributed to the larger ground level sensitivity of the MAX-DOAS instrument with respect to the FTIR instrument as will be shown later. Compared to the instrument at UNAM, the FTIR instrument located at Altzomoni, presents lower HCHO VCD hourly mean values. This is to be expected, since that instrument is located at a higher altitude level (>1700 m higher than UNAM) and therefore above the mixed layer most of the time and thus probes cleaner atmospheric columns, as long as there is no upslope transport.

Figure 2 shows the diurnal cycle of hourly averaged HCHO from FTIR (red), MAX-DOAS V3 (blue), MAXDOAS V1 (magenta) and MAX-DOAS V2 (cyan) measurements at UNAM. The VCD hourly averages from the MAXDOAS instrument are in general larger than those from the FTIR instrument ( $0 \%$ to $38 \%$ for V1, $15 \%$ to $47 \%$ for V2 and $29 \%$ to $61 \%$ for V3); however, both exhibit a similar pattern throughout the day. The results from the FTIR measurements show a steady increase of HCHO VCDs from early morning until 13:00 LT, when the HCHO VCDs start to slightly decrease until the end of the measurement day. The results from the MAX-DOAS instrument also show a decrease after 13:00 LT but show an increase at 16:00 LT, likely due to traffic during rush hour. A decrease of primary $\mathrm{HCHO}$ (to $32 \%$ or less) in the afternoon was reported by Lei et al. (2009), a behavior not necessarily observed in the measurements reported in this study for the MAX-DOAS datasets. The slight increase of the HCHO column from 16:00 LT (MAX-DOAS datasets) could be an indication of the contribution of secondary $\mathrm{HCHO}$ becoming more important in the atmospheric column in the afternoon. It should however be noted that the conclusions presented by Lei et al. (2009) are based on a modeled $3 \mathrm{~d}$ episode case study constrained by ground-based measurements (conducted during the MCMA2003 field campaign) at one site, while the results presented in the current study are based on more than 8 years of measurements of the amount of $\mathrm{HCHO}$ in the tropospheric column. This situation could explain the differences in the observations reported in this study and by Lei et al. (2009).

In Fig. 3, the seasonal (monthly average) HCHO VCD cycle of FTIR (red), MAX-DOAS V3 (blue), MAX-DOAS V1 (magenta) and MAX-DOAS V2 (cyan) measurements at UNAM is presented. As in the case of the diurnal cycle, MAX-DOAS HCHO VCDs are larger than the ones reported by the FTIR measurement technique ( $2 \%$ to $35 \%$ for V1, $17 \%$ to $51 \%$ for V2 and $23 \%$ to $75 \%$ for V3); nevertheless, the two datasets are within each other's temporal variability. Both instruments show two maxima: May and September for the MAX-DOAS and May and October for the FTIR measurements. In addition, both instruments present the lowest HCHO VCDs values during January and December.

\subsection{HCHO horizontal distribution from OMI satellite observations}

In order to assess the horizontal inhomogeneity of $\mathrm{HCHO}$ in the MCMA, an average distribution map of $\mathrm{HCHO}$ was constructed from data between 2005 and 2018 from the Ozone Monitoring Instrument (OMI) satellite instrument and is presented in Fig. 4. The OMHCHO Version3 (OMI/Aura Formaldehyde (HCHO) Total Column 1-orbit L2 Swath $13 \times 24 \mathrm{~km}$ V003) data product (Chance, 2007) was downloaded from the Earthdata web portal. The map was generated using the "ReferenceSectorCorrectedVerticalColumn" field from the SAO OMI (Smithsonian Astrophysical Observatory Ozone Monitoring Instrument) product (González Abad et al., 2015). Only data with a cloud fraction of $20 \%$ or less and the field "MainDataQualityFlag" set to zero were used. From this average HCHO distribution map, a strong horizontal inhomogeneity over the MCMA is evident and motivates the investigation of the differences in computing VCDs using MAX-DOAS measurements conducted towards the eastern (V1) or western (V2) sides of the scanning plane or using all available measurements (V3), as will be described below.

\subsection{MAX-DOAS versus FTIR comparison at UNAM}

\subsubsection{Differences in the MAX-DOAS viewing directions}

A detailed comparison between VCDs retrieved using the MAX-DOAS and FTIR measurement techniques was conducted and is explained in this section. The correlation between the coincident hourly mean vertical columns from FTIR and MAX-DOAS measured at UNAM are shown in Fig. 5. The plots shown in the left column contain the re- 


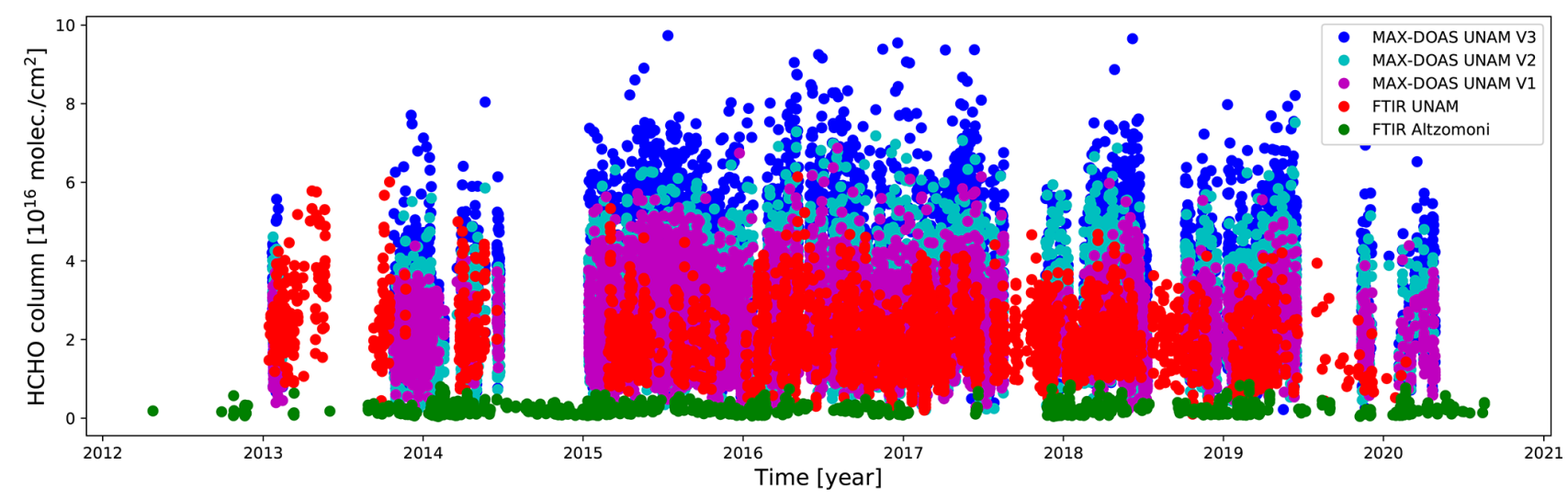

Figure 1. Hourly means of HCHO vertical column densities (VCDs) from the MAX-DOAS instrument at UNAM (V1, magenta; V2, cyan; and V3, blue) and the solar-absorption FTIR instrument at UNAM (red) and at Altzomoni (green). The measurements in Mexico City at the UNAM campus (red, magenta, cyan and blue) are 1 order of magnitude higher than the background measurements at the mountain site of Altzomoni (green). The same applies to their variance. The difference between the MAX-DOAS and FTIR measurements at UNAM is mainly explained by their averaging kernel and is discussed in detail in the text. The altitude ranges covered by each instrument are as follows: for the FTIR instrument at UNAM, VCDs of 2-16 km; for the FTIR instrument at Altzomoni, VCDs of 4-16 km; and for the MAX-DOAS instrument at UNAM, VCDs of $2-5 \mathrm{~km}$.

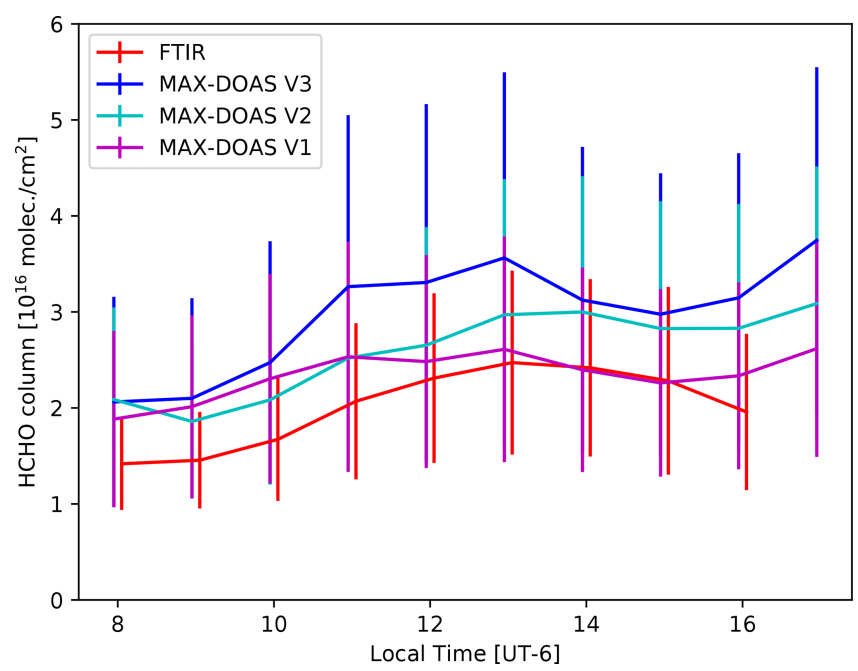

Figure 2. Diurnal cycle from hourly averaged HCHO VCDs from FTIR (red), MAX-DOAS V3 (blue), MAX-DOAS V1 (magenta) and MAX-DOAS V2 (cyan) measurements at UNAM. Vertical lines represent the standard deviation of all conducted measurements during that hour.

trieved VCDs without any correction. Four different datasets are presented in the different rows from top to bottom corresponding to four product versions: V1 retrieved VCDs from MAX-DOAS measurements conducted towards the east; V2 retrieved VCDs from MAX-DOAS measurements conducted towards the west; V3 retrieved VCDs from MAX-DOAS measurements conducted towards both sides of the scanning plane; and in the fourth row V1 retrieved VCDs from MAX-DOAS measurements conducted towards the east during the morning hours, and V2 retrieved VCDs from MAX-

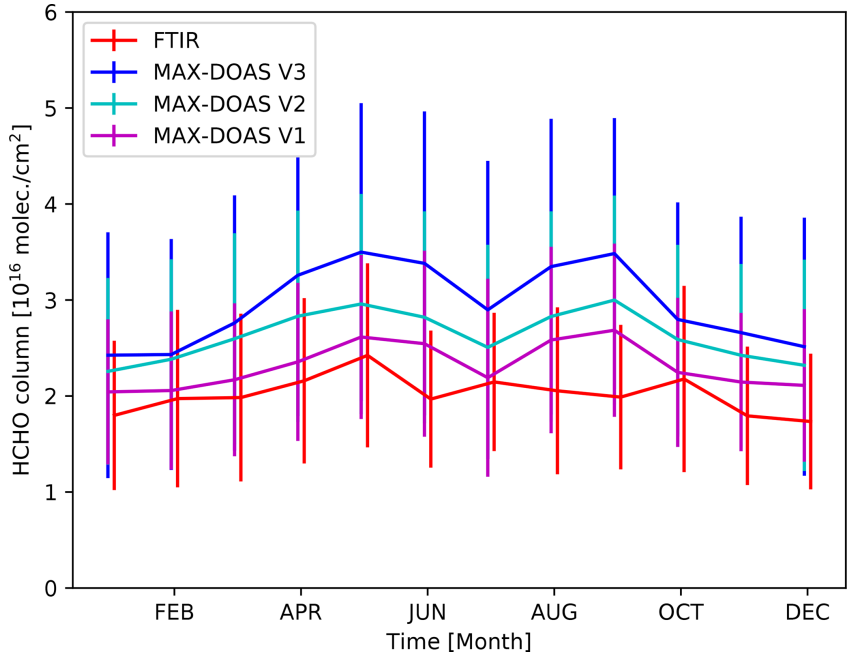

Figure 3. Seasonal FTIR (red), MAX-DOAS V3 (blue), MAXDOAS V1 (magenta) and MAX-DOAS V2 (cyan) cycles at UNAM. Vertical lines represent the standard deviation of all conducted measurements during each month.

DOAS measurements conducted towards the west during the afternoon hours. The correlation coefficient is provided, along with the linear regression information when forced to zero (red) and not constrained (green). Black lines represent the $1: 1$ relation. The resulting total column averaging kernel from the retrievals of the FTIR and MAXDOAS datasets are presented in the third column of Fig. 5, which already explains partly the relation between the vertical columns. The total column averaging kernel is the sum of the rows of the averaging kernel in partial columns [molec. $\mathrm{cm}^{-2} /$ molec. $\mathrm{cm}^{-2}$ ]. The averaging kernel of the 


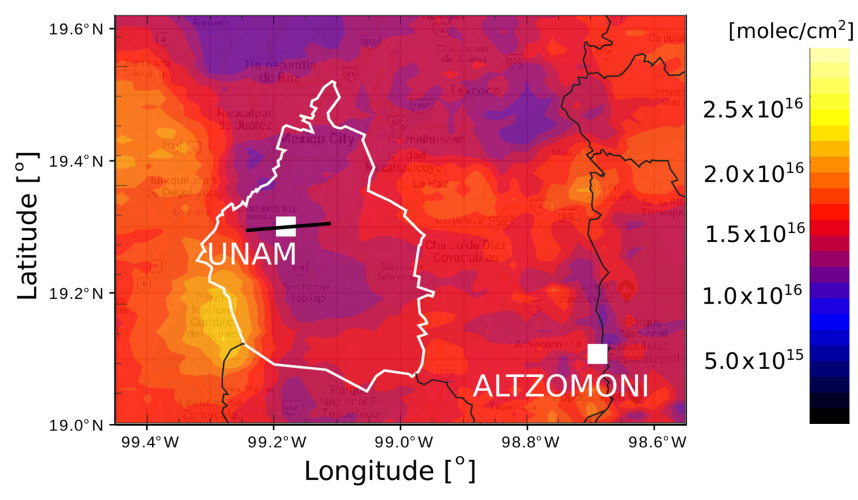

Figure 4. Average $\mathrm{HCHO}$ total column distribution map over the MCMA between 2005 and 2018. The columnar HCHO distribution is reconstructed from OMI measurements on board the Aura satellite with a daily Mexico City overpass at around 14:00 LT (spatial distribution is only representative for this time). Color bar units are in molec. $\mathrm{cm}^{-2}$. The UNAM and Altzomoni measurement sites are marked with a square; the region comprising Mexico City is indicated in white; and the measurement directions are indicated with a black line over the UNAM site.

FTIR measurement is lower than 1.0 within the mixed layer (2280-4000 $\mathrm{m}$ a.s.1.), containing the largest amount of $\mathrm{HCHO}$, and thus the VCD is underestimated. It can be seen that the V1 dataset has a better agreement (slope closer to 1) than V2 and V3. It is interesting to note that particularly the VCDs retrieved from MAX-DOAS using both measurement directions (third row) have an enhanced sensitivity in comparison to the FTIR retrieval, which partly explains the slope of $1.28 \%$ and the $28 \%$ overestimation with respect to the FTIR retrievals. The comparison between FTIR and MAXDOAS data based on the coincidence of the measurement geometry (V1 retrieved VCDs from MAX-DOAS measurements conducted towards the east during the morning hours and V2 retrieved VCDs from MAX-DOAS measurements conducted towards the west during the afternoon hours) presented in the fourth row provides the best agreement among the datasets.

For the correlation plots presented in the middle column of Fig. 5, the retrieved MAX-DOAS profiles were smoothed with the FTIR averaging kernels resulting typically in lower MAX-DOAS VCD values. This smoothing process simulates how the HCHO profile retrieved by the MAX-DOAS should be seen by the FTIR instrument. The smoothed profiles are calculated by multiplying the averaging kernel of the FTIR retrieval with the retrieved MAX-DOAS profile (Rodgers, 2000). For the V3 dataset, the smoothing by the FTIR kernel improves the slope from 1.28 to 1.11 , and much more might not be expected, as the vertical information in the MAXDOAS profiles is limited to less than 2 degrees of freedom (average values being 0.692 for $\mathrm{V} 1,0.782$ for $\mathrm{V} 2$ and 0.970 for V3) and do not represent the true atmospheric profile, while the average FTIR degrees of freedom is 1.0 for the
UNAM site and 1.1 for the Altzomoni site (Vigouroux et al., 2018). For a fair comparison, the effect of the different a priori information (Fig. 6) in the retrieval is taken into account, and the new a priori information for both retrievals is the average of the MAX-DOAS profile retrieval of V3.

To further investigate the large $\mathrm{HCHO}$ inhomogeneity already shown in Fig. 4, VCDs from the MAX-DOAS products using different viewing directions (V1, V2 and V3) were analyzed independently. Figure 7 shows correlation plots between the coincident HCHO VCDs when using dSCDs measured towards the east (a) or the west (b) compared to HCHO VCDs computed using both sides of the scanning plane. Black lines represent the 1:1 relation, and a linear regression not constrained to zero is shown in green. The correlation between datasets for the east (V1) and both sides (V3) results in a Pearson correlation coefficient of 0.887 with a slope of 0.630 and an offset of $6.781 \times 10^{15}$ molec. $\mathrm{cm}^{-2}$. When comparing west (V2) versus both sides (V3), the calculated Pearson correlation coefficient is 0.908 with a slope of 0.722 and an offset of $5.616 \times 10^{15}$ molec. $\mathrm{cm}^{-2}$. VCDs retrieved using measurements from both sides of the scanning plane are in general larger than VCDs retrieved using data from measurements of only one of the sides. This result can be explained by the larger amount of information available for the retrievals when dSCDs in different elevation angles and both scanning directions are used (average degrees of freedom values being 0.692 for V1, 0.782 for V2 and 0.970 for V3) (Fig. 8). However, a conclusive explanation from this analysis cannot be derived without investigating the time-dependent differences observed using different viewing directions.

\subsubsection{Time-dependent differences in the MAX-DOAS viewing directions}

The hourly differences between VCDs computed using the eastern or western sides of the scanning plane is investigated further; therefore simulated VCDs were calculated in order to compare them with measured VCDs. Simulated VCDs eastwest differences are the result of the different amount of information in the retrievals in V1 and V2. The true profile has much higher $\mathrm{HCHO}$ concentrations in the polluted mixing layer than what the a priori information reflects. The retrieval using both sides of the measurement plane contains more information originating from the measurements and allows the result on an optimal-estimation-based retrieval to be less close to the a priori information. The V1 and V2 retrievals do not always have the same amount of information, as the filtering criteria for the spectra do not act similarly throughout the day, and spectral measurements are selected in an unbalanced way. The factors affecting the uneven amount of information used in the retrievals include permanent or temporal obstacles and the time-dependent probability of saturation of the spectra when viewing towards or close to the sun. This means that even if the atmosphere around the measurement 

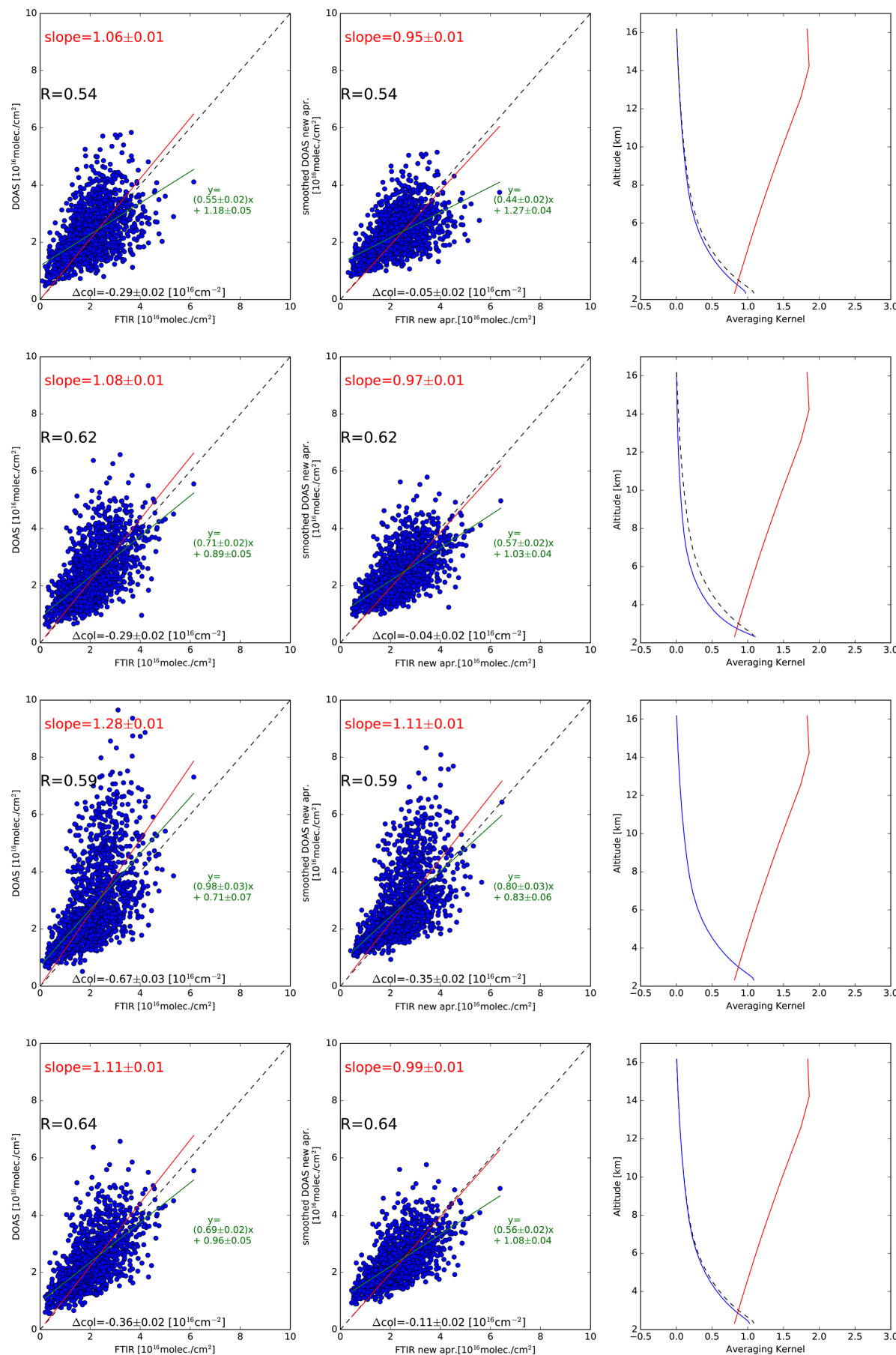

Figure 5. Comparison between FTIR and MAX-DOAS measurements conducted at the UNAM measurement site. The panels in the first and second rows correspond to the VCDs retrieved from MAX-DOAS measurements conducted towards the eastern (V1) and western (V2) measurement sides, respectively. For the third row panel, corresponding to the V3 data product, the VCDs are retrieved including both measurement sides. The panels in the fourth row correspond to the comparison between FTIR and MAX-DOAS V1 measurements during the morning and FTIR and MAX-DOAS V2 measurements during the afternoon. The linear regression when forced to zero (red) and not constrained (green) is presented. Black lines represent the $1: 1$ relation. The left column shows the direct correlation between coincident pairs, whereas the middle column compares the retrieved FTIR VCDs with those calculated from the smoothed MAX-DOAS profiles using the averaging kernel from the FTIR instrument (see text). The right column shows the total column averaging kernel of the FTIR (red lines) and MAX-DOAS (blue lines) retrievals. The dashed black lines on the first, second and fourth rows represent the averaging kernel of V3. A priori: apr. 

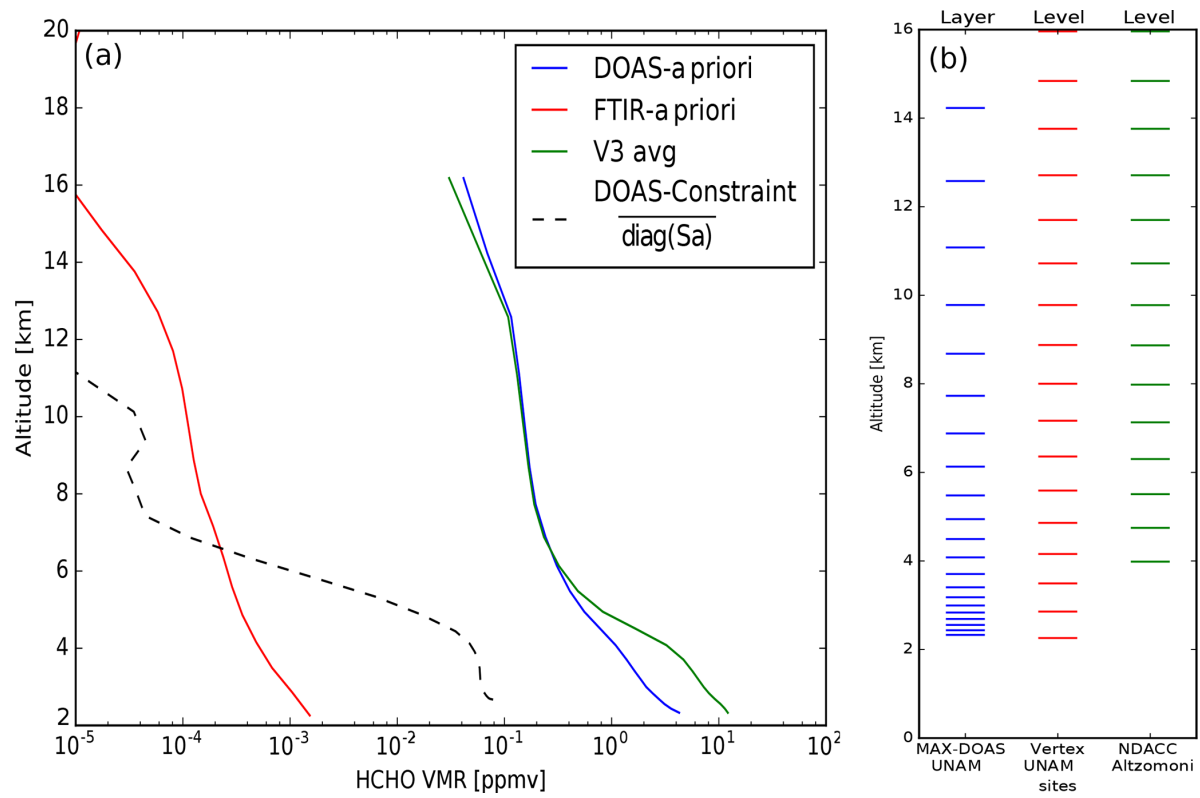

Figure 6. (a) A priori information for the MAX-DOAS and FTIR retrievals. The blue line is the a priori information used in the MAX-DOAS retrieval; the black dashed line shows the square root of the Sa matrix in the MAX-DOAS retrieval regularized according to optimal estimation (OE). As commonly used for FTIR retrievals that form part of the NDACC network, a priori information taken from the WACCAM model was used. The green line is the average of the MAX-DOAS instrument retrieved HCHO profiles (V3, both sides) and gives an idea about the vertical distribution of HCHO above UNAM. This averaged profile is used as common a priori information for the improved intercomparison between MAX-DOAS and FTIR instruments. (b) Vertical grids of the MAX-DOAS and FTIR (both measurement sites) inversions. Diagonal: diag.

site would be perfectly homogeneous in the horizontal plane, the columns retrieved using V1 and V2 datasets might be slightly different. We try to explain this by the different sensitivities and their averaging kernels $\left(\mathrm{AK}, \mathrm{AK}_{\text {east }}^{\text {tot }}, \mathrm{AK}_{\text {west }}^{\text {tot }}\right.$ and their difference $\Delta \mathrm{AK}_{\text {east-west }}^{\text {tot }}$, through the following equations.

$$
x_{\text {ret }}-x_{\text {apr }}=\mathrm{AK}\left(x_{\text {true }}-x_{\text {apr }}\right)+\epsilon
$$

Equation 1 (Rodgers, 2000) describes how the retrieved profile is related to the true profile and how other quantities such as the total column can be derived. It is described by the following equation, where $\boldsymbol{g}^{\text {tot }}$ defines the total column operator for profiles $\boldsymbol{g}^{\text {tot }}{ }_{i}=\frac{\partial \mathrm{col}}{\partial x_{i}}$.

$$
\begin{aligned}
\mathrm{col}-\mathrm{col}_{\text {apr }} & =\boldsymbol{g}^{\text {tot }}\left(\boldsymbol{x}_{\text {ret }}-\boldsymbol{x}_{\text {apr }}+\boldsymbol{\epsilon}\right) \\
& =\operatorname{AK}^{\mathrm{tot}}\left(\boldsymbol{x}_{\text {true }}-\boldsymbol{x}_{\text {apr }}\right)+\epsilon_{\mathrm{col}}
\end{aligned}
$$

Here we choose $\boldsymbol{x}$ in the units of partial columns [molec. $\mathrm{cm}^{-2}$ ] so that $\mathrm{AK}^{\text {tot }}$ is without units as shown in the last column of Fig. 5.

$$
\begin{aligned}
& \operatorname{col}_{\text {east }}=\mathrm{AK}_{\text {east }}^{\text {tot }}\left(x_{\text {true }}-x_{\text {apr }}\right)+\operatorname{col}_{\text {apr }}+\epsilon_{1} \\
& \operatorname{col}_{\text {west }}=\operatorname{AK}_{\text {west }}^{\text {tot }}\left(x_{\text {true }}-\boldsymbol{x}_{\text {apr }}\right)+\operatorname{col}_{\text {apr }}+\epsilon_{2}
\end{aligned}
$$

If the errors $\epsilon_{1}$ and $\epsilon_{2}$ of each harmonized retrieval pair have a random and systematic component, the systematic component is canceled out for each pair, while the random components result in $\epsilon_{1,2}$, which should be zero in the average of a sufficiently large number of measurement pairs.

$$
\Delta \text { col }_{\text {east-west }}=\left(\mathrm{AK}_{\text {east }}^{\mathrm{tot}}-\mathrm{AK}_{\text {west }}^{\mathrm{tot}}\right)\left(\boldsymbol{x}_{\text {true }}-\boldsymbol{x}_{\mathrm{apr}}\right)+\epsilon_{1,2}
$$

If we assume that the retrieved profile $\boldsymbol{x}_{\boldsymbol{v} \mathbf{3}}$, using both sides of the measurement plane, is to our current knowledge the best estimation for the $\mathrm{HCHO}$ profile (if one assumes horizontal homogeneity) $\boldsymbol{x}_{\text {true }}$, we use it to simulate the expected differences $\Delta$ col $_{\text {east-west }}$.

$\Delta$ col $_{\text {east-west }} \approx \Delta \mathrm{AK}_{\text {east-west }}^{\mathrm{tot}}\left(\boldsymbol{x}_{v 3}-\boldsymbol{x}_{\mathrm{apr}}\right)$

This expected or simulated difference, which evidently depends on the time of the day, is calculated according to Eq. (6), and the results are shown in Fig. 9 (red line), along with the measured VCD hourly differences. In this case, the specific distinction is made between the calculated east-west 

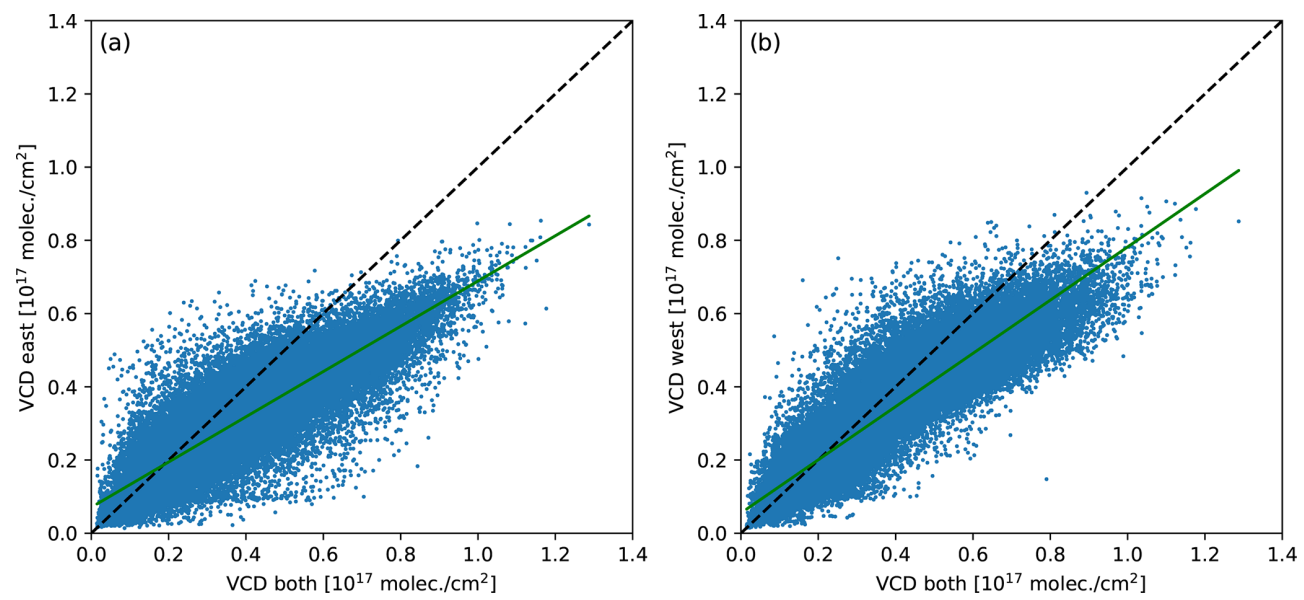

Figure 7. Correlation plots between HCHO VCDs retrieved using dSCDs measured towards the (a) east and (b) west with respect to VCDs retrieved using information from both sides ( $x$ axis). The green lines indicate the linear regression fits, and the black lines represent the $1: 1$ relation.
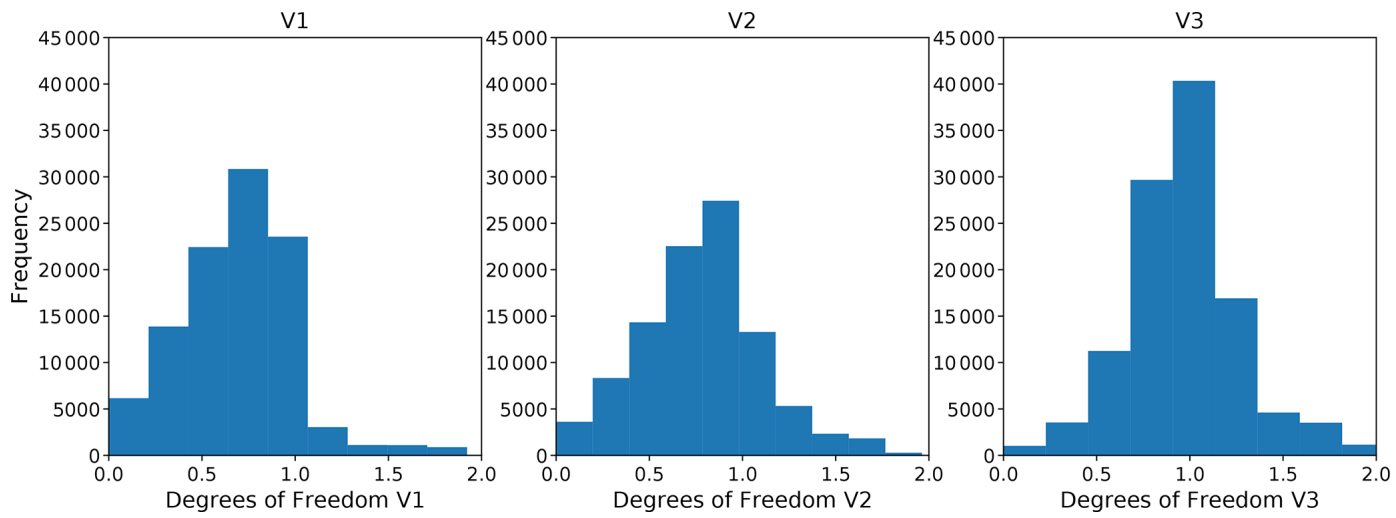

Figure 8. Histograms showing degrees of freedom and frequencies for V1, V2 and V3 retrievals.

differences of the retrieved VCDs (blue), a simulated VCD difference explained above (red) and the resulting difference between these (calculated-simulated) in black dots.

The averaging kernels from the V1 and V2 retrievals allow us to estimate and forecast a difference because of their different sensitivities. This effect, dominant after 15:00 LT, most likely depends on the number of dSCDs available for the MMF retrievals that could be significantly reduced, as the sun is closer to the viewing angles and does not pass the filtering criteria due to saturation. Alternatively, the forward model in QDOAS could be having more difficulties in explaining the measured spectra so that the errors in the retrieved dSCDs (typically $15 \%$ for the lowest elevation angles where the HCHO signal is expected to be higher) could be enhanced and thus unweighted in the MMF model calculations during these afternoon hours due to saturation or the presence of clouds towards the west. The detailed reasons for imbalanced information content between the east and west retrievals are, however, not yet investigated. Nevertheless, the calculation of the red line uses the $\mathrm{HCHO}$ profile retrieved in
$\mathrm{V} 3$, as it is probably the best estimation available, but it is of course not the true profile, and the meaningfulness of Eq. (6) is therefore limited to be qualitative. Without grouping in different hours of the day, both differences originating from the gradient and from the information content cancel partly out and would not show a conclusive result.

As can be seen in Fig. 9, the simulated line resembles the calculated VCD differences (blue line), and both lines present higher positive differences in the morning hours and a decline towards negative values in the afternoon and hence indicate that a large part of the observed difference is due to differences in information content and not necessarily due to different real distributions. However, the difference between the calculated and simulated lines, shown as black dots, gives us a better indication of the relative $\mathrm{HCHO}$ abundances along the east-west viewing direction. During the morning hours, this calculated difference has positive values demonstrating that the abundance of $\mathrm{HCHO}$ on the eastern side of the scanning plane is higher than on the western side. After 12:00 LT, conditions change so that larger HCHO VCDs are mea- 


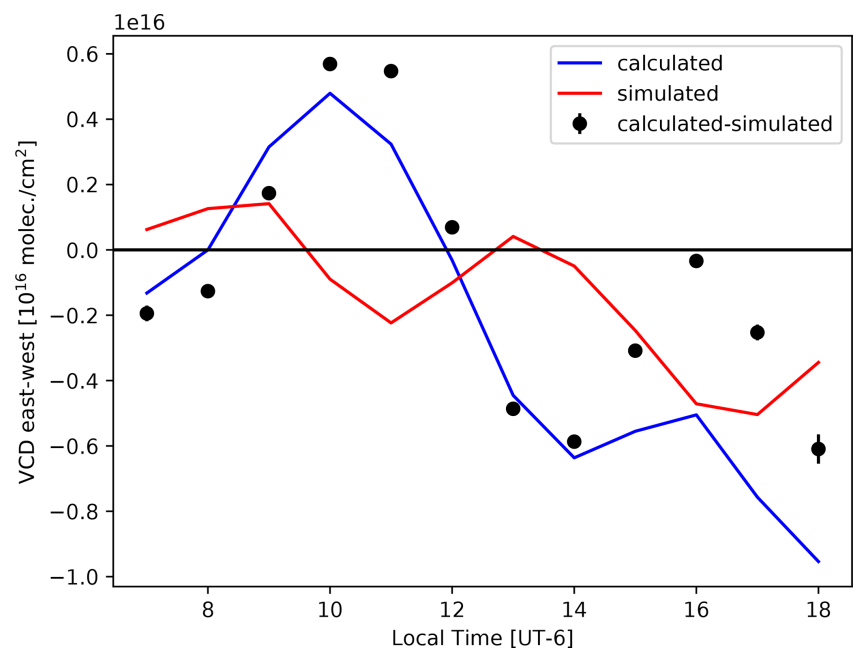

Figure 9. Average differences between the retrieved columns using the east and west measurement sides, as function of the hour of the day, are presented in the blue line. The red line simulates how the information available from the retrievals would produce a difference in the columns, assuming that the retrieval of the V3 dataset using both measurement sides best describes the atmospheric state (see text for details). The black points are the difference between the found differences and the "forecasted" differences and should show the part of the difference which might be related to a real inhomogeneity and a gradient between the east and the west $\mathrm{HCHO}$ concentrations in the mixing layer. The error bars represent the standard error and show that the measurement amount is large enough to calculate a statistically significant mean difference for each day by hour, and the grouping for different hours is necessary.

sured towards the western side of the scanning plane, peaking at 13:00-14:00. The average HCHO distribution over the MCMA, reconstructed from OMI data (Fig. 4), provides evidence of a larger enhancement of HCHO columns towards the western side of the MCMA at the OMI overpass time, coinciding with our findings in terms of the identified horizontal inhomogeneity as well as timing. Afterwards, the situation appears to slightly return to the circumstances where $\mathrm{HCHO}$ is more evenly distributed in both directions and might be even a bit higher towards the east at around 16:00. The observed changes could also be related to orographic and meteorological conditions. Fast et al. (2007) report that surface wind measurements over the MCMA indicate the production of strong convergence in the basin during the late afternoon, created by opposing propagating density currents and a gap flow originating in the southeastern corner of the basin. The authors conclude that in the MCMA short-range transport can be produced by the complex terrain surrounding it, producing local and regional circulations.

\subsubsection{Time-dependent MAX-DOAS versus FTIR comparison}

In the previous section, it was shown that analyzing the MAX-DOAS viewing directions independently can in part explain the large horizontal inhomogeneity around the UNAM urban site. We now investigate the behavior in the correlation between MAX-DOAS and FTIR data for different hours of the day and how it can be affected by the sensitivities of both instruments and the changing vertical distribution of the HCHO profiles.

Figure 10 shows the comparison of hourly MAX-DOAS (V3) versus FTIR measurements at UNAM. For each hour the correlation coefficient is provided, along with the linear regression information when forced to zero (red) and not constrained (green). Black lines represent the $1: 1$ relation. In the lower-right panel, the FTIR and MAX-DOAS averaging kernels as a function of altitude are plotted for each hour, not showing significant variability. Hourly correlation coefficients range between 0.66 at 11:00, 14 and 15:00 and 0.52 at 13:00, while slopes vary between $1.62(12: 00)$ and 0.92 (15:00). It is interesting to point out that the slope steadily increases between 09:00 (1.24) and noon (1.62), the latter being the precise inflection point where the MAX-DOAS instrument reports a significant change in the HCHO VCDs horizontal distribution (Fig. 9). At 13:00 (1.43) the slope starts to decrease until it stabilizes at 15:00-16:00 (0.92 and 0.96 , respectively). On the other hand, the correlation coefficient decreases between 11:00 (0.66) and 13:00 (0.52), increasing afterwards, reaching a final value of 0.63 at 16:00.

The relation between the MAX-DOAS and the FTIR VCDs is described by the scatter (the Pearson correlation coefficient), the slope and constant bias. As we already have seen in the comparison between the MAX-DOAS V3 data product (both sides) with respect to the single sides, having a slope of 1.0 does not ensure that both retrievals are correct and similar to the true atmospheric state, but it rather means that both sensitivities are similar.

Based on Eq. (1) (Rodgers, 2000) and assuming that the variability in the $\mathrm{HCHO}$ concentration profile can be described by a Gaussian probability distribution with the mean profile $\left(\boldsymbol{x}_{\text {mean }}\right)$ and a covariance matrix Sa (unfortunately not known), the Pearson correlation and the slope in the scatter plot of two retrievals can be calculated using the averaging kernels and the errors of both retrievals.

Neither the retrieved FTIR profile (1.1) nor the MAXDOAS profile retrieval $(<2)$ have sufficient degrees of freedom to consider the retrieval as profile retrieval; therefore the strategy of using the profile information from one instrument together with the averaging kernel of the other instrument is not too promising.

Here we try to evaluate the consistency of the two retrievals differently, starting with Eq. (2) and assuming that both instruments are measuring coincidently the same atmospheric state $\boldsymbol{x}_{\text {true }}$. 

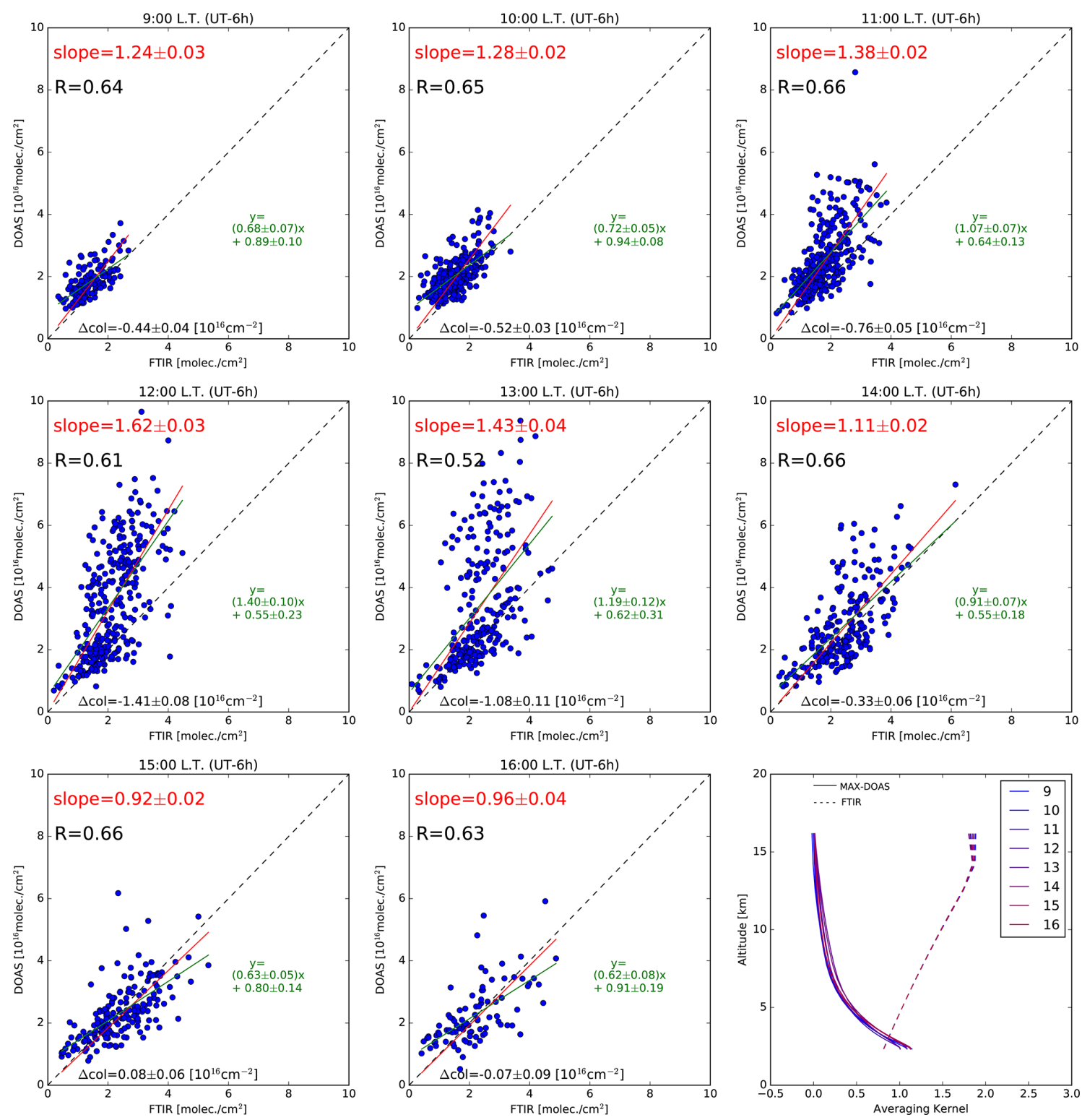

Figure 10. Hourly FTIR versus MAX-DOAS comparisons at UNAM between 09:00 and 16:00 LT.

The average of the product of the columns of both instruments is theoretically given by the following equation; for that purpose we introduce the errors $\epsilon_{\mathrm{FTIR}}(i)$ and $\epsilon_{\mathrm{DOAS}}(i)$, where $i$ is the index which identifies a certain hour:

$\left\langle\Delta \operatorname{col}_{\text {DOAS }} \cdot \Delta \operatorname{col}_{\mathrm{FTIR}}\right\rangle=$

$$
\begin{aligned}
& \frac{1}{N} \sum_{i}^{N}\left[\operatorname{AK}_{\mathrm{DOAS}}^{\mathrm{tot}}(i)\left(\boldsymbol{x}_{\text {true }}(i)-\boldsymbol{x}_{\mathrm{apr}}\right)+\epsilon_{\mathrm{DOAS}}(i)\right] \\
& \cdot\left[\mathrm{AK}_{\mathrm{FTIR}}^{\mathrm{tot}}(i)\left(\boldsymbol{x}_{\text {true }}(i)-\boldsymbol{x}_{\mathrm{apr}}\right)+\epsilon_{\mathrm{FTIR}}(i)\right] .
\end{aligned}
$$

To simplify the interpretation, we assume that the averaging kernels of both instruments are more or less constant and independent in $i$, where $i$ is the index for the hours for which coincident measurements exist. This assumption is valid for the FTIR averaging kernel (Fig. 10 and Eq. 7), but it is not the case for the MAX-DOAS measurements, and it is therefore an approximation, which might be verified in each case. Another simplification is the assumption that the retrievals are corrected using the same a priori $x_{\text {apr }}$ profile, which is also the mean of the true profiles $x_{\text {true }}$ of the ensembles. So the average of $\Delta$ col DOAS $_{\text {Dn }} \Delta \mathrm{col}_{\mathrm{FTIR}}$ are zero. In addition we assume that the errors $\epsilon_{\mathrm{FTIR}}(i)$ and $\epsilon_{\mathrm{DOAS}}(i)$ are independent and in average zero; we assume also that they are indepen- 
dent with respect to $\mathrm{AK}_{\mathrm{DOAS}}^{\mathrm{tot}}(i), \mathrm{AK}_{\mathrm{FTIR}}^{\mathrm{tot}}(i)$ and $\boldsymbol{x}_{\text {true }}(i)$ so that we can simplify the calculation of Eq. (7) as Eq. (8).

$$
\begin{aligned}
& \frac{1}{N} \sum_{i}^{N} \mathrm{AK}_{\mathrm{DOAS}}^{\mathrm{tot}} \underbrace{\left[\left(\boldsymbol{x}_{\text {true }}(i)-\boldsymbol{x}_{\mathrm{apr}}\right) \cdot\left(\boldsymbol{x}_{\text {true }}(i)-\boldsymbol{x}_{\mathrm{apr}}\right)^{T}\right]}_{\text {Sa }} \\
& \cdot\left(\mathrm{AK}_{\mathrm{FTIR}}^{\mathrm{tot}}\right)^{T},
\end{aligned}
$$

and therefore the Pearson correlation coefficient and the slope are formally calculated:

$$
\begin{aligned}
& R_{\text {pearson }}= \\
& \frac{\left(\mathrm{AK} K_{\mathrm{DOAS}}^{\mathrm{tot}}\right) \cdot \mathbf{S a} \cdot\left(\mathrm{AK}_{\mathrm{FTIR}}^{\mathrm{tot}}\right)^{T}}{\sqrt{\left.\left(\left(\mathrm{AK}_{\mathrm{DOAS}}^{\mathrm{tot}}\right) \cdot \mathbf{S a} \cdot\left(\mathrm{AK}_{\mathrm{DOAS}}^{\mathrm{tot}}\right)^{T}+\sigma_{\mathrm{DOAS}}^{2}\right)\left(\left(\mathrm{AK}_{\mathrm{FTIR}}^{\mathrm{tot}}\right) \cdot \mathbf{S a} \cdot\left(\mathrm{AK}_{\mathrm{FTTR}}^{\mathrm{tot}}\right)^{T}+\sigma_{\mathrm{FTIR}}^{2}\right)\right)}},
\end{aligned}
$$

slope $=\frac{\left(\mathrm{AK}_{\mathrm{DOAS}}^{\mathrm{tot}}\right) \cdot \mathbf{S a} \cdot\left(\mathrm{AK}_{\mathrm{FTIR}}^{\mathrm{tot}}\right)^{T}}{\left(\mathrm{AK}_{\mathrm{FTIR}}^{\mathrm{tot}}\right) \cdot \mathbf{S a} \cdot\left(\mathrm{AK}_{\mathrm{FTIR}}^{\mathrm{tot}}\right)^{T} .}$

If the correlation plot is limited to just $1 \mathrm{~h}$ as shown in Fig. 10, the Sa just describes the variability in that hour. For a certain time of the day it is more probable that the variability and covariance matrix $\mathbf{S a}$ is described by a single dominant eigenvector $\mathbf{S a}=\boldsymbol{v} \cdot \boldsymbol{v}^{T}$. If the errors $\sigma_{\text {DOAS }}$ and $\sigma_{\text {FTIR }}$ in the columns of MAX-DOAS and FTIR can be neglected, the resulting Pearson correlation coefficient would be 1.0 according to Eq. (9), and the slope would be given by $\left(\mathrm{AK}_{\mathrm{DOAS}}^{\mathrm{tot}} \cdot \boldsymbol{v}\right) /\left(\mathrm{AK}_{\mathrm{FTIR}}^{\mathrm{tot}} \cdot \boldsymbol{v}\right)$, the quotient of the weighted averaged total column averaging-kernel elements using the weights $\boldsymbol{v}$.

The variability of the concentration profile with a fixed shape $\left(\boldsymbol{v}=\lambda_{v} \boldsymbol{e}_{v}\right.$, with $\left.\lambda_{v}=|\boldsymbol{v}|\right)$ from a single day to another has a strong impact on the Pearson correlation coefficient $R$ (more variation with respect to the errors (FTIR and MAXDOAS) results in a better $R$ value) but not on the value of the slope. The slope is given by the averaging kernels of the two instruments and the shape of the variable profile $\boldsymbol{v}$. In Mexico City, we could assume that at 09:00 LT the mixing layer is well mixed with $\mathrm{HCHO}$ up to a certain height with a constant concentration but with zero or at least a constant $\mathrm{HCHO}$ value above this height. For this simple assumption (the only eigenvector is constant in the mixing layer but zero above it), the slope is the fraction of the mean averaging-kernel elements in the mixing layer (MAX-DOAS and FTIR). In case we cannot explain the experimental measured slopes, we learn that there are some other processes involved, which are not described by the simplified Sa. Maybe there might be sometimes also a pollution plume above this well-mixed layer.

The individual plots in Fig. 10, showing the correlations and their slopes for each hour, allow us to support the fact that instead of simply cross validating the FTIR and MAXDOAS retrievals, it is possible to assume that the mixinglayer height dominates the variability and that such simplification is valid at a certain hour. The validation is therefore given by the fact that a plausible variability for each hour explains the slope and correlation for different hours rather than that the slope and the correlation is close to 1.0.

\subsection{Background HCHO variability in a remote site}

In order to investigate background $\mathrm{HCHO}$ levels, $\mathrm{HCHO}$ VCDs retrieved from measurements conducted with the high-resolution FTIR spectrometer (Bruker Optics, IFS120/5 HR) in Altzomoni are presented in Fig. 11. HCHO VCDs measured at Altzomoni are in the same order of magnitude as HCHO VCDs reported by Vigouroux et al. (2018) for several "clean" sites stations belonging to the NDACC network, such as Zugspitze, and other mountain sites (however at a latitude of $47^{\circ}$ and an altitude of $3 \mathrm{~km}$ ), as well as for Mauna Loa, at a latitude of $20^{\circ}$ and an altitude of $3.4 \mathrm{~km}$.

As in the case of the UNAM measurement site, the diurnal and seasonal $\mathrm{HCHO}$ cycles were calculated. Hourly $\mathrm{HCHO}$ VCDs at Altzomoni show a steady increase during the day, with a smaller growth rate from 14:00 to 17:00. Vigouroux et al. (2018) report the same behavior (a maximum in the late afternoon between 16:00 and 18:00 LT) for other stations of the NDACC network: Bremen, Paris, Toronto and Lauder. Further analysis should be conducted regarding the diurnal HCHO cycle at Altzomoni; however the detected maximum at late afternoon could be attributed to upslope transport or to secondary $\mathrm{HCHO}$ production that has reached a maximum at a certain hour of the day.

The seasonal cycle shows a maximum during September, while the lowest HCHO VCDs values occur during December. The background HCHO VCDs at Altzomoni (Fig. 11) are an order of magnitude lower than the values reported at the urban UNAM measurement site for both the diurnal (Fig. 2) and seasonal (Fig. 3) cycles.

\section{Discussion and conclusions}

In this contribution we present a comparison between HCHO total column densities retrieved from two independent measurement techniques: MAX-DOAS and solarabsorption FTIR. Both measurement techniques, although based on spectroscopy, exhibit a very different measurement strategy and geometry. Despite these differences, a good agreement was obtained between both instruments. Due to the versatility of the retrieval code used to process the MAXDOAS data, VCDs were retrieved using measurements conducted towards different viewing directions. Retrieval products were obtained employing measurements conducted exclusively towards the east or the west or using measurements conducted towards both sides of the measurement station. Considering the FTIR results as the reference, MAX-DOAS VCDs from these datasets where $6 \%, 8 \%$ and $28 \%$ larger than FTIR, respectively. 

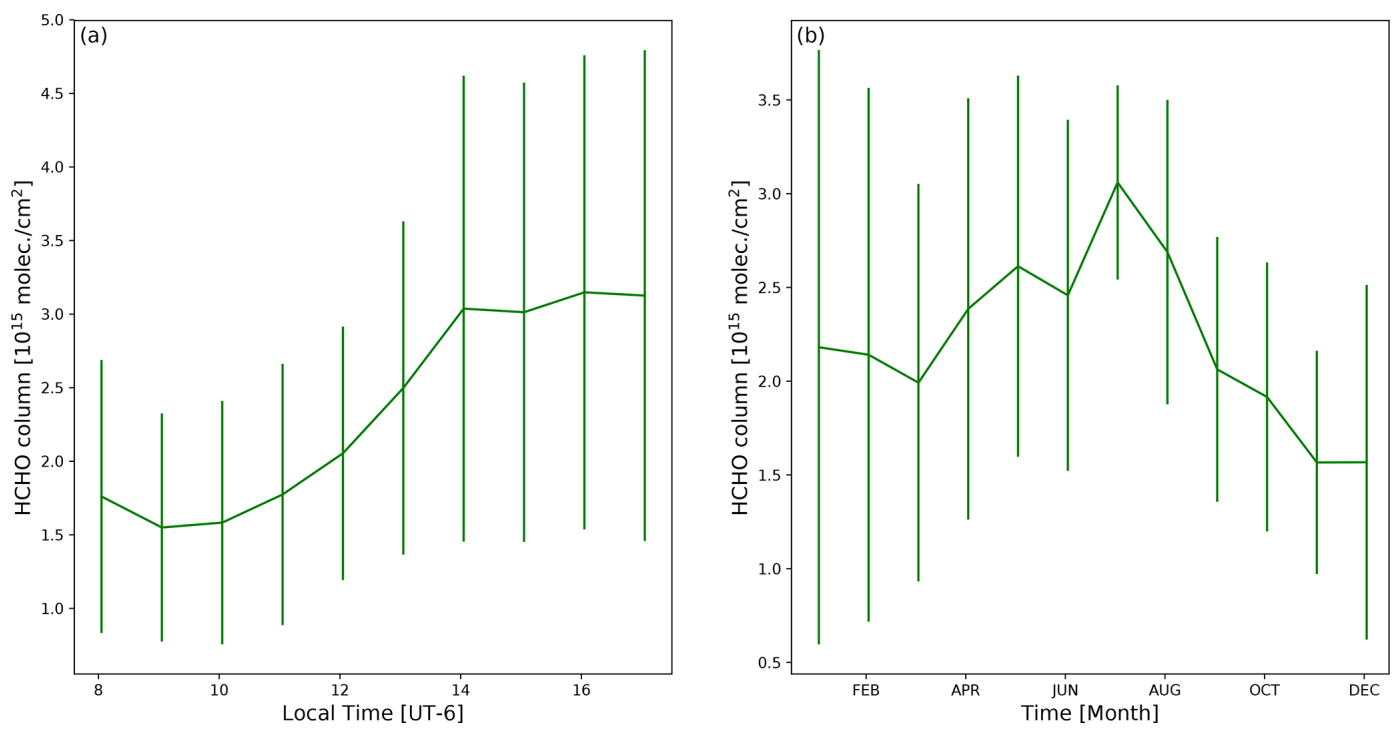

Figure 11. Hourly (a) and seasonal (b) HCHO VCD cycles at Altzomoni from FTIR measurements.

Reasons for the overestimation of the MAX-DOAS over the FTIR results are attributed to an enhanced ground level (lowest few kilometers of the atmosphere) sensitivity of the former with respect to the latter. However, the intrinsic differences between the two measurement techniques could also account for the discrepancies found in this study. In the first place, both measurement techniques have different sampling geometries and strategies. The MAX-DOAS instrument measures spectra at different elevation angles, leading to an altitude-averaged measurement in the lower atmosphere. From these measurements, HCHO VCDs are computed using a numerical code - MMF (Friedrich et al., 2019). For the MAX-DOAS instrument, typically, a complete cycle encompassing several observations may take several minutes, which could be a disadvantage during periods of rapidly varying radiation transport conditions in the atmosphere, such as varying cloud cover, aerosol load, or during sunrise and sunset. The distance from which photons are scattered and reach the instrument's telescope is variable, and depending on atmospheric conditions and the wavelength it has been calculated to be between 0.6 and $6 \mathrm{~km}$ (Platt and Stutz, 2008). Meanwhile, the FTIR instrument receives direct sunlight so that the air mass sampled by the instrument comes from a well-defined cone angle smaller than the solar disk (external field of view around $7 \mathrm{mrad}$ at UNAM and $2 \mathrm{mrad}$ at Altzomoni), and the time resolution of the FTIR spectra are described by the measurement duration and frequency. The measurement duration and time distance are a 1 min duration and every $5 \mathrm{~min}$ at UNAM and a 7 min duration and every 21 min at Altzomoni. After computations, the direct-sun total HCHO column is delivered. Further characterization of the differences between both measurement techniques, for example by using the same sampling geometry, is a work in progress for the Spectroscopy and Remote Sensing
Group at CCA-UNAM and in the future will provide further insights into the differences and possible biases between the two techniques due to distinctive spectroscopic characteristics and retrieval approaches. In addition, a different analysis approach could be taken in the future, by using and presenting both datasets (FTIR and MAX-DOAS) as complementary to each other, since due to the different sensitivities of the measurement techniques, the retrieved information does not refer exactly to the same altitudes of the atmosphere.

Moreover, this research provided the opportunity to study in more detail horizontal HCHO inhomogeneities in the MCMA, identifying diurnal and seasonal variabilities of the abundance of HCHO total columns. In the future this could be used to further study primary versus secondary $\mathrm{HCHO}$ in the MCMA and develop specific analysis strategies focused on the identification and disaggregation of freshly emitted and secondary produced $\mathrm{HCHO}$ in the boundary layer of the MCMA. Satellite-based data have been used to corroborate the spatial inhomogeneity of the HCHO total column over the MCMA as shown in Fig. 4, strengthening the importance of continuing these types of inhomogeneity studies at different azimuthal angles, in different zones of the MCMA and also focusing on other atmospheric constituents. The identified inhomogeneity of $\mathrm{HCHO}$ in Mexico City could be investigated even further by using the lowest elevation angles of the MAX-DOAS data (i.e., near-surface $\mathrm{HCHO}$ ) at the different azimuth angles.

Identifying and characterizing horizontal inhomogeneities with respect to the abundance of molecules present in air can also be of service when making decisions regarding location and azimuth measurement angles for future MAXDOAS stations in the MCMA. Future work includes studying horizontal inhomogeneities at other stations of the MAXDOAS network as well as horizontal inhomogeneities of 
other chemical species, such as nitrogen dioxide, which is routinely retrieved as well from the spectra measured by the MAX-DOAS instruments located in the MCMA.

It is worth mentioning that these types of strong spatial heterogeneity scenarios have been observed in different areas of the planet and specific studies of atmospheric constituents have been or are currently being performed in other urbanized and densely populated areas such as North America (Boeke et al., 2011; Chance et al., 2000; Millet et al., 2008); China (Cheng et al., 2015; Zhang et al., 2019), particularly in the Beijing-Tianjin-Hebei region (Zhu et al., 2018); and the Yangtze River Delta area (Chan et al., 2019; Hong et al., 2018; Tian et al., 2018; Wang et al., 2016); and southern Asia (Rana et al., 2019), more specifically India (Chutia et al., 2019; Surl et al., 2018) and Pakistan (Khan et al., 2018; Khokhar et al., 2015). In addition specific case studies have been conducted globally (Wittrock et al., 2006) or in the Southern Hemisphere (Ahn et al., 2019), the Atlantic Ocean (Behrens et al., 2019) and the East China Sea (Tan et al., 2018). Findings of these studies imply the enhanced abundance of $\mathrm{HCHO}$ over highly populated areas, areas with increased industrial activity, zones exhibiting biogenic emissions and biomass burning activities and along major highways, and in some instances these identify cases of regional transport of pollutants.

The quantified diurnal and seasonal variability of $\mathrm{HCHO}$ as well as the characterized horizontal inhomogeneity in the MCMA, presented in this study, could be attributed to direct emissions or secondary formation of $\mathrm{HCHO}$ from released precursors from anthropogenic and/or biogenic sources that form part of the MCMA and constantly influence its atmospheric composition. Identification of either primary emissions or secondary formation of $\mathrm{HCHO}$ is outside the scope of this study; however, based on the results presented here and previous research conducted by Garcia et al. (2006), future analyses could include studying other molecules present in the atmosphere as tracers of primary or secondary HCHO.

In terms of further characterizing $\mathrm{HCHO}$ horizontal inhomogeneity, the Tropospheric Emissions: Monitoring of Pollution (TEMPO) instrument (Zoogman et al., 2017), an airborne mission to be launched in the near future, will allow us to corroborate the hourly horizontal changes in the $\mathrm{HCHO}$ distribution over the MCMA that have been identified in this study.

Data availability. The MAX-DOAS and FTIR data can be accessed via http://www.epr.atmosfera.unam.mx/maxdoas_data/hcho/ (Rivera et al., 2021.) and http://www.epr.atmosfera.unam.mx/ftir data/HCHO/ (Stremme et al., 2021), respectively. Data from other stations, with other versions or periods measured within Mexico City's MAX-DOAS network, should be requested from Claudia Rivera (claudia.rivera@atmosfera.unam.mx).
Author contributions. CR was responsible for the QDOAS retrieval setup and parameter choices, for the setup and running of the MMF code, for processing $\mathrm{HCHO}$ OMI data, and data analysis and interpretation. CR wrote parts of the Abstract and parts of Sects. 2, 3 and 4. CG was responsible for developing and optimizing various HCHO retrievals for Altzomoni and UNAM and contributed to the development of the NDACC retrieval strategy, which was finally applied. CG took care of the measurements and focused on the separation of freshly emitted $\mathrm{HCHO}$ and secondary produced $\mathrm{HCHO}$ in the boundary layer of Mexico City. WS wrote parts of Sects. 2 and 3. MMF was responsible for the retrieval MMF code development and testing, the retrieval chain setup from spectra to profiles, and the retrieval parameter choices for MMF and software support. MMF wrote parts of Sect. 2. DR was responsible for running parts of the MMF code. CAMR was responsible for processing HCHO OMI data and assisted in the creation of Fig. 4. AB provided technical support for instruments and data management. MG was involved in the data interpretation and wrote Sect. 1 and parts of Sects. 2, 3 and 4. WS, AB and MG were responsible for running the FTIR retrievals at UNAM and Altzomoni and for data analysis and interpretation. TB and FH provided the IFS120/5 HR spectrometer located in Altzomoni and developed the setup of the spectrometer and solar tracker. They provided assistance by bringing the spectrometer in Altzomoni into operation and trained the Mexican group in the operation and alignment of the IFS120/5 HR. FH developed the retrieval code PROFFIT9 and LINEFIT and provided continuous support during its use. In terms of specific figures contributions, Figs. 1, 2 and 3 were created by WS and CR; Fig. 4 was created by CR and CAMR; Figs. 5 and 6 were created by WS; Figs. 7, 8 and 9 were created by WS, DR and CR; and Figs. 10 and 11 were created by WS.

Competing interests. The authors declare that they have no conflict of interest.

Acknowledgements. Arne Krueger, Josué Arellano, Alfredo Rodríguez, Delibes Flores, Miguel Angel Robles and Omar López are thanked for their technical assistance. We thank Caroline Fayt (caroline.fayt@aeronomie.be), Michel Van Roozendael (michelv@aeronomie.be) and Thomas Danckaert for the free use of the QDOAS software, and we thank Robert Spurr for free use of the VLIDORT radiative transfer code package. We thank Agustin García Reynoso for important and fruitful discussions about $\mathrm{HCHO}$ in Mexico City. We thank the Mexican Solarimetric Service for their effort in establishing and maintaining the AERONET Mexico City site. We thank the University of Wyoming Department of Atmospheric Science for providing the sounding data on http: //weather.uwyo.edu/upperair/sounding.html (last access: 29 April 2020).

Financial support. This research has been supported by the DGAPA-UNAM (grant nos. TA100418, IN111418, IN107417 and IA101620), the CONACYT (grant no. 290589) and the INECC (grant no. INECC-A1-002-2019). Cristina A. Mendoza-Rodríguez received financial support from Consejo Nacional de Ciencia y Tecnología (CONACYT) through a graduate studies grant (no. CVU 
956921). Wolfgang Stremme received financial support from DGAPA-PASPA.

Review statement. This paper was edited by Michel Van Roozendael and reviewed by two anonymous referees.

\section{References}

Ahn, D. H., Choi, T., Kim, J., Park, S. S., Lee, Y. G., Kim, S.-J., and Koo, J.-H.: Southern Hemisphere mid- and high-latitudinal $\mathrm{AOD}, \mathrm{CO}, \mathrm{NO}_{2}$, and $\mathrm{HCHO}$ : spatiotemporal patterns revealed by satellite observations, Progress in Earth and Planetary Science, 6, 34, https://doi.org/10.1186/s40645-019-0277-y, 2019.

Arellano, J., Krüger, A., Rivera, C., Stremme, W., Friedrich, M., Bezanilla, A., and Grutter, M.: The MAX-DOAS network in Mexico City to measure atmospheric pollutants, Atmosfera, 29, 157-167, https://doi.org/10.20937/ATM.2016.29.02.05, 2016.

Baylon, J. L., Stremme, W., Grutter, M., Hase, F., and Blumenstock, T.: Background $\mathrm{CO}_{2}$ levels and error analysis from groundbased solar absorption IR measurements in central Mexico, Atmos. Meas. Tech., 10, 2425-2434, https://doi.org/10.5194/amt10-2425-2017, 2017.

Behrens, L. K., Hilboll, A., Richter, A., Peters, E., Alvarado, L. M. A., Kalisz Hedegaard, A. B., Wittrock, F., Burrows, J. P., and Vrekoussis, M.: Detection of outflow of formaldehyde and glyoxal from the African continent to the Atlantic Ocean with a MAX-DOAS instrument, Atmos. Chem. Phys., 19, 1025710278, https://doi.org/10.5194/acp-19-10257-2019, 2019.

Bezanilla, A., Krüger, A., Stremme, W., and Grutter, M.: Solar absorption infrared spectroscopic measurements over Mexico City: Methane enhancements, Atmósfera, 27, 173-183, 2014.

Boeke, N. L., Marshall, J. D., Alvarez, S., Chance, K. V., Fried, A., Kurosu, T. P., Rappenglück, B., Richter, D., Walega, J., Weibring, P., and Millet, D. B.: Formaldehyde columns from the Ozone Monitoring Instrument: Urban versus background levels and evaluation using aircraft data and a global model, J. Geophys. Res.-Atmos., 116, D05303, https://doi.org/10.1029/2010JD014870, 2011.

Chan, K. L., Wang, Z., Ding, A., Heue, K.-P., Shen, Y., Wang, J., Zhang, F., Shi, Y., Hao, N., and Wenig, M.: MAX-DOAS measurements of tropospheric $\mathrm{NO}_{2}$ and $\mathrm{HCHO}$ in Nanjing and a comparison to ozone monitoring instrument observations, Atmos. Chem. Phys., 19, 10051-10071, https://doi.org/10.5194/acp-19-10051-2019, 2019.

Chance, K.: OMI/Aura Formaldehyde (HCHO) Total Column 1orbit L2 Swath $13 \times 24$ km V003, Greenbelt, MD, USA, Goddard Earth Sciences Data and Information Services Center (GES DISC), https://doi.org/10.5067/Aura/OMI/DATA2015, 2007.

Chance, K. and Kurucz, R.: An improved high-resolution solar reference spectrum for earth's atmosphere measurements in the ultraviolet, visible, and near infrared, J. Quant. Spectrosc. Ra., 111, 1289-1295, https://doi.org/10.1016/j.jqsrt.2010.01.036, 2010.

Chance, K., Palmer, P. I., Spurr, R. J. D., Martin, R. V., Kurosu, T. P., and Jacob, D. J.: Satellite observations of formaldehyde over North America from GOME, Geophys. Res. Lett., 27, 34613464, https://doi.org/10.1029/2000GL011857, 2000.
Chance, K. V. and Spurr, R. J. D.: Ring effect studies: Rayleigh scattering, including molecular parameters for rotational Raman scattering, and the Fraunhofer spectrum, Appl. Opt., 36, 52245230, https://doi.org/10.1364/AO.36.005224, 1997.

Cheng, M., Jiang, H., Guo, Z., Zhang, X., and Chen, J.: Correlation between the spatio-temporal distributions of aerosols, sulphur dioxide, and formaldehyde using MODIS and SCIAMACHY satellite data for China, Int. J. Remote Sens., 36, 3961-3978, https://doi.org/10.1080/01431161.2015.1070317, 2015.

Chutia, L., Ojha, N., Girach, I. A., Sahu, L. K., Alvarado, L. M., Burrows, J. P., Pathak, B., and Bhuyan, P. K.: Distribution of volatile organic compounds over Indian subcontinent during winter: WRF-chem simulation versus observations, Environ, Pollut,, 252, 256-269, https://doi.org/10.1016/j.envpol.2019.05.097, 2019.

Danckaert, T., Fayt, C., Van Roozendael, M., De Smedt, I., Letocart, V., Merlaud, A., and Pinardi, G.: QDOAS Software user manual, Belgian Institute for Space Aeronomy, available at: http://uv-vis. aeronomie.be/software/QDOAS/QDOAS_manual.pdf (last access: 19 January 2021), 2017.

Fast, J. D., de Foy, B., Acevedo Rosas, F., Caetano, E., Carmichael, G., Emmons, L., McKenna, D., Mena, M., Skamarock, W., Tie, X., Coulter, R. L., Barnard, J. C., Wiedinmyer, C., and Madronich, S.: A meteorological overview of the MILAGRO field campaigns, Atmos. Chem. Phys., 7, 2233-2257, https://doi.org/10.5194/acp-7-2233-2007, 2007.

Finlayson-Pitts, B. J. and Pitts, J. N.: Chemistry of the upper and lower atmosphere: theory, experiments, and applications, Academic Press, San Diego, CA, 2000.

Fleischmann, O. C., Hartmann, M., Burrows, J. P., and Orphal, J.: New ultraviolet absorption cross-sections of $\mathrm{BrO}$ at atmospheric temperatures measured by time-windowing Fourier transform spectroscopy, J. Photoch. Photobio. A, 168, 117-132, https://doi.org/10.1016/j.jphotochem.2004.03.026, 2004.

Franco, B., Hendrick, F., Van Roozendael, M., Müller, J.-F., Stavrakou, T., Marais, E. A., Bovy, B., Bader, W., Fayt, C., Hermans, C., Lejeune, B., Pinardi, G., Servais, C., and Mahieu, E.: Retrievals of formaldehyde from ground-based FTIR and MAX-DOAS observations at the Jungfraujoch station and comparisons with GEOS-Chem and IMAGES model simulations, Atmos. Meas. Tech., 8, 1733-1756, https://doi.org/10.5194/amt-81733-2015, 2015.

Friedrich, M. M., Rivera, C., Stremme, W., Ojeda, Z., Arellano, J., Bezanilla, A., García-Reynoso, J. A., and Grutter, M.: $\mathrm{NO}_{2}$ vertical profiles and column densities from MAX-DOAS measurements in Mexico City, Atmos. Meas. Tech., 12, 2545-2565, https://doi.org/10.5194/amt-12-2545-2019, 2019.

Garcia, A. R., Volkamer, R., Molina, L. T., Molina, M. J., Samuelson, J., Mellqvist, J., Galle, B., Herndon, S. C., and Kolb, C. E.: Separation of emitted and photochemical formaldehyde in Mexico City using a statistical analysis and a new pair of gas-phase tracers, Atmos. Chem. Phys., 6, 4545-4557, https://doi.org/10.5194/acp-6-4545-2006, 2006.

Gisi, M.: Setup of precise camera based solar tracker systems and greenhouse gas measurements using a modified portable spectrometer, Ph.D. thesis, Karlsruher Instituts für Technologie, available at: https://publikationen.bibliothek.kit. edu/1000031248 (last access: 20 January 2021), 2012. 
Gisi, M., Hase, F., Dohe, S., and Blumenstock, T.: Camtracker: a new camera controlled high precision solar tracker system for FTIR-spectrometers, Atmos. Meas. Tech., 4, 47-54, https://doi.org/10.5194/amt-4-47-2011, 2011.

González Abad, G., Liu, X., Chance, K., Wang, H., Kurosu, T. P., and Suleiman, R.: Updated Smithsonian Astrophysical Observatory Ozone Monitoring Instrument (SAO OMI) formaldehyde retrieval, Atmos. Meas. Tech., 8, 19-32, https://doi.org/10.5194/amt-8-19-2015, 2015.

Grutter, M., Flores, E., Andraca-Ayala, G., and Báez, A.: Formaldehyde levels in downtown Mexico City during 2003, Atmos. Environ., 39, 1027-1034, https://doi.org/10.1016/j.atmosenv.2004.10.031, 2005.

Hase, F., Hannigan, J., Coffey, M., Goldman, A., Höpfner, M., Jones, N., Rinsland, C., and Wood, S.: Intercomparison of retrieval codes used for the analysis of high-resolution, groundbased FTIR measurements, J. Quant. Spectrosc. Ra., 87, 25-52, 2004.

Hendrick, F., Dils, B., Gielen, C., Langerock, B., Pinardi, G., De Mazière, M., Van Roozendael, M., Peters, E., Richter, A., Piters, A., Beirle, S., Wagner, T., Drosoglou, T., Bais, A., Wang, S., Cuevas, C., and Saiz-Lopez, A.: Historical record of independent reference data for $\mathrm{NO}_{2}, \mathrm{HCHO}$, and $\mathrm{CO}$, Tech. Rep. QA4ECV Report / Deliverable 3.8-Draft version 1.0, IASB-BIRA, Brussels, Belgium, available at: http://www. qa4ecv.eu/sites/default/files/QA4ECV_D3.8_v1.0_web.pdf (last access: 19 January 2021), 2016.

Hong, Q., Liu, C., Chan, K. L., Hu, Q., Xie, Z., Liu, H., Si, F., and Liu, J.: Ship-based MAX-DOAS measurements of tropospheric $\mathrm{NO}_{2}, \mathrm{SO}_{2}$, and $\mathrm{HCHO}$ distribution along the Yangtze River, Atmos. Chem. Phys., 18, 5931-5951, https://doi.org/10.5194/acp18-5931-2018, 2018.

Kesselmeier, J., Bode, K., Hofmann, U., Müller, H., Schäfer, L., Wolf, A., Ciccioli, P., Brancaleoni, E., Cecinato, A., Frattoni, M., Foster, P., Ferrari, C., Jacob, V., Fugit, J., Dutaur, L., Simon, V., and Torres, L.: Emission of short chained organic acids, aldehydes and monoterpenes from Quercus ilex L. and Pinus pinea L. in relation to physiological activities, carbon budget and emission algorithms, Atmos. Environ., 31, 119-133, https://doi.org/10.1016/S1352-2310(97)00079-4, 1997.

Khan, W. A., Khokhar, M. F., Shoaib, A., and Nawaz, R.: Monitoring and analysis of formaldehyde columns over Rawalpindi-Islamabad, Pakistan using MAX-DOAS and satellite observation, Atmos. Pollut. Res., 9, 840-848, https://doi.org/10.1016/j.apr.2017.12.008, 2018.

Khokhar, M. F., Khalid, T., Yasmin, N., and Smedt, I. D.: SpatioTemporal Analyses of Formaldehyde over Pakistan by Using SCIAMACHY and GOME-2 Observations, Aerosol Air Qual. Res., 15, 1760-1773, https://doi.org/10.4209/aaqr.2014.12.0339, 2015.

Kreher, K., Van Roozendael, M., Hendrick, F., Apituley, A., Dimitropoulou, E., Frieß, U., Richter, A., Wagner, T., Lampel, J., Abuhassan, N., Ang, L., Anguas, M., Bais, A., Benavent, N., Bösch, T., Bognar, K., Borovski, A., Bruchkouski, I., Cede, A., Chan, K. L., Donner, S., Drosoglou, T., Fayt, C., Finkenzeller, H., Garcia-Nieto, D., Gielen, C., Gómez-Martín, L., Hao, N., Henzing, B., Herman, J. R., Hermans, C., Hoque, S., Irie, H., Jin, J., Johnston, P., Khayyam Butt, J., Khokhar, F., Koenig, T. K., Kuhn, J., Kumar, V., Liu, C., Ma, J., Merlaud, A., Mishra, A. K., Müller,
M., Navarro-Comas, M., Ostendorf, M., Pazmino, A., Peters, E., Pinardi, G., Pinharanda, M., Piters, A., Platt, U., Postylyakov, O., Prados-Roman, C., Puentedura, O., Querel, R., Saiz-Lopez, A., Schönhardt, A., Schreier, S. F., Seyler, A., Sinha, V., Spinei, E., Strong, K., Tack, F., Tian, X., Tiefengraber, M., Tirpitz, J.L., van Gent, J., Volkamer, R., Vrekoussis, M., Wang, S., Wang, Z., Wenig, M., Wittrock, F., Xie, P. H., Xu, J., Yela, M., Zhang, C., and Zhao, X.: Intercomparison of $\mathrm{NO}_{2}, \mathrm{O}_{4}, \mathrm{O}_{3}$ and $\mathrm{HCHO}$ slant column measurements by MAX-DOAS and zenith-sky UVvisible spectrometers during CINDI-2, Atmos. Meas. Tech., 13, 2169-2208, https://doi.org/10.5194/amt-13-2169-2020, 2020.

Lei, W., Zavala, M., de Foy, B., Volkamer, R., Molina, M. J., and Molina, L. T.: Impact of primary formaldehyde on air pollution in the Mexico City Metropolitan Area, Atmos. Chem. Phys., 9, 2607-2618, https://doi.org/10.5194/acp-9-2607-2009, 2009.

Meller, R. and Moortgat, G. K.: Temperature dependence of the absorption cross sections of formaldehyde between 223 and $323 \mathrm{~K}$ in the wavelength range $225-375 \mathrm{~nm}$, J. Geophys. Res.-Atmos., 105, 7089-7101, https://doi.org/10.1029/1999JD901074, 2000.

Millet, D. B., Jacob, D. J., Boersma, K. F., Fu, T.-M., Kurosu, T. P., Chance, K., Heald, C. L., and Guenther, A.: Spatial distribution of isoprene emissions from North America derived from formaldehyde column measurements by the OMI satellite sensor, J. Geophys. Res.-Atmos., 113, D02307, https://doi.org/10.1029/2007JD008950, 2008.

Pinardi, G., Van Roozendael, M., Abuhassan, N., Adams, C., Cede, A., Clémer, K., Fayt, C., Frieß, U., Gil, M., Herman, J., Hermans, C., Hendrick, F., Irie, H., Merlaud, A., Navarro Comas, M., Peters, E., Piters, A. J. M., Puentedura, O., Richter, A., Schönhardt, A., Shaiganfar, R., Spinei, E., Strong, K., Takashima, H., Vrekoussis, M., Wagner, T., Wittrock, F., and Yilmaz, S.: MAXDOAS formaldehyde slant column measurements during CINDI: intercomparison and analysis improvement, Atmos. Meas. Tech., 6, 167-185, https://doi.org/10.5194/amt-6-167-2013, 2013.

Platt, U. and Stutz, J.: Differential Optical Absorption Spectroscopy, Springer-Verlag, Berlin, Heidelberg, https://doi.org/10.1007/978-3-540-75776-4, 2008.

Plaza-Medina, E. F., Stremme, W., Bezanilla, A., Grutter, M., Schneider, M., Hase, F., and Blumenstock, T.: Ground-based remote sensing of $\mathrm{O}_{3}$ by high- and medium-resolution FTIR spectrometers over the Mexico City basin, Atmos. Meas. Tech., 10, 2703-2725, https://doi.org/10.5194/amt-10-2703-2017, 2017.

Rana, A., Parvez, S., Ul-Haq, Z., Batool, S., Chaudhary, M., Mamhood, K., and Tariq, S.: Anthropogenic, biogenic and pyrogenic emission sources and atmospheric formaldehyde ( $\mathrm{HCHO})$ and nitrogen dioxide $\left(\mathrm{NO}_{2}\right)$ columns over different landuse/landcovers of South Asia, Appl. Ecol. Env. Res., 17, 1098911015, https://doi.org/10.15666/aeer/1705_1098911015, 2019.

Rivera, C., Bezanilla, A., and Grutter, M.: HCHO MAX-DOAS retrievals of this work, available at: http://www.epr.atmosfera. unam.mx/maxdoas_data/hcho/, last access: 21 January 2021.

Rodgers, C. D.: Inverse Methods for Atmospheric Sounding: Theory and Practice, World Scientific Publishing Co, Singapore, https://doi.org/10.1142/3171, 2000.

Seinfeld, J. and Pandis, S.: Atmospheric Chemistry and Physics: From Air Pollution to Climate Change, Wiley, available at: https: //books.google.com.mx/books?id=J3s30hwn_K0C (last acccess: 20 January 2021), 2012. 
Serdyuchenko, A., Gorshelev, V., Weber, M., Chehade, W., and Burrows, J. P.: High spectral resolution ozone absorption crosssections - Part 2: Temperature dependence, Atmos. Meas. Tech., 7, 625-636, https://doi.org/10.5194/amt-7-625-2014, 2014.

Solal, C., Rousselle, C., Mandin, C., Manel, J., and Maupetit, F.: VOCs and formaldehyde emissions from cleaning products and air fresheners, in: 11. International Conference on Indoor Air Quality and Climate (Indoor Air 2008), p. Paper ID: 183, Copenhague, Denmark, available at: https://hal-ineris.archives-ouvertes.fr/ineris-00973310 (last access: 20 January 2021), 2008.

Spurr, R.: VLIDORT: A linearized pseudo-spherical vector discrete ordinate radiative transfer code for forward model and retrieval studies in multilayer multiple scattering media, J. Quant. Spectrosc. Ra., 102, 316-342, 2006.

Spurr, R.: User's Guide VLIDORT Version 2.6, RT Solutions, Inc., available at: http://web.gps.caltech.edu/ vijay/userguides/ vlidort_2p6_f90userguide_v12_08feb2013_NC.pdf (last access: 20 January 2021), 2013.

Spurr, R. J. D., Kurosu, T. P., and Chance, K. V.: A linearized discrete ordinate radiative transfer model for atmospheric remote-sensing retrieval, J. Quant. Spectrosc. Ra., 68, 689-735, https://doi.org/10.1016/S0022-4073(00)00055-8, 2001.

Stavrakou, T., Müller, J.-F., De Smedt, I., Van Roozendael, M., van der Werf, G. R., Giglio, L., and Guenther, A.: Evaluating the performance of pyrogenic and biogenic emission inventories against one decade of space-based formaldehyde columns, Atmos. Chem. Phys., 9, 1037-1060, https://doi.org/10.5194/acp-91037-2009, 2009.

Stremme, W., Bezanilla, A., and Grutter, M.: HCHO FTIR retrievals of this work, available at: http://www.epr.atmosfera.unam.mx/ ftir_data/HCHO/, last access: 21 January 2021.

Stremme, W., Ortega, I., and Grutter, M.: Using ground-based solar and lunar infrared spectroscopy to study the diurnal trend of carbon monoxide in the Mexico City boundary layer, Atmos. Chem. Phys., 9, 8061-8078, https://doi.org/10.5194/acp-9-8061-2009, 2009.

Surl, L., Palmer, P. I., and González Abad, G.: Which processes drive observed variations of HCHO columns over India?, Atmos. Chem. Phys., 18, 4549-4566, https://doi.org/10.5194/acp18-4549-2018, 2018.

Tan, W., Liu, C., Wang, S., Xing, C., Su, W., Zhang, C., Xia, C., Liu, H., Cai, Z., and Liu, J.: Tropospheric $\mathrm{NO}_{2}, \mathrm{SO}_{2}$, and $\mathrm{HCHO}$ over the East China Sea, using ship-based MAX-DOAS observations and comparison with OMI and OMPS satellite data, Atmos. Chem. Phys., 18, 15387-15402, https://doi.org/10.5194/acp-1815387-2018, 2018.

Taquet, N., Stremme, W., Grutter, M., Baylón, J., Bezanilla, A., Schiavo, B., Rivera, C., Campion, R., Boulesteix, T., Nieto-Torres, A., Espinasa-Pereña, R., Blumenstock, T., and Hase, F.: Variability in the Gas Composition of the Popocatépetl Volcanic Plume, Front. Earth Sci., 7, 114, https://doi.org/10.3389/feart.2019.00114, 2019.

Taubenböck, H., Esch, T., Felbier, A., Wiesner, M., Roth, A., and Dech, S.: Monitoring urbanization in mega cities from space, Remote Sens. Environ., 117, 162-176, https://doi.org/10.1016/j.rse.2011.09.015,, 2012.

Thalman, R. and Volkamer, R.: Temperature dependent absorption cross-sections of $\mathrm{O}_{2}-\mathrm{O}_{2}$ collision pairs between 340 and $630 \mathrm{~nm}$ and at atmospherically relevant pressure, Phys. Chem. Chem. Phys., 15, 15371-15381, https://doi.org/10.1039/C3CP50968K, 2013.

Tian, X., Xie, P., Xu, J., Li, A., Wang, Y., Qin, M., and Hu, Z.: Long-term observations of tropospheric $\mathrm{NO}_{2}, \mathrm{SO}_{2}$ and $\mathrm{HCHO}$ by MAX-DOAS in Yangtze River Delta area, China, J. Environ. Sci., 71, 207-221, https://doi.org/10.1016/j.jes.2018.03.006, 2018.

Tirpitz, J.-L., Frieß, U., Hendrick, F., Alberti, C., Allaart, M., Apituley, A., Bais, A., Beirle, S., Berkhout, S., Bognar, K., Bösch, T., Bruchkouski, I., Cede, A., Chan, K. L., den Hoed, M., Donner, S., Drosoglou, T., Fayt, C., Friedrich, M. M., Frumau, A., Gast, L., Gielen, C., Gomez-Martín, L., Hao, N., Hensen, A., Henzing, B., Hermans, C., Jin, J., Kreher, K., Kuhn, J., Lampel, J., Li, A., Liu, C., Liu, H., Ma, J., Merlaud, A., Peters, E., Pinardi, G., Piters, A., Platt, U., Puentedura, O., Richter, A., Schmitt, S., Spinei, E., Stein Zweers, D., Strong, K., Swart, D., Tack, F., Tiefengraber, M., van der Hoff, R., van Roozendael, M., Vlemmix, T., Vonk, J., Wagner, T., Wang, Y., Wang, Z., Wenig, M., Wiegner, M., Wittrock, F., Xie, P., Xing, C., Xu, J., Yela, M., Zhang, C., and Zhao, $\mathrm{X}$.: Intercomparison of MAX-DOAS vertical profile retrieval algorithms: studies on field data from the CINDI-2 campaign, Atmos. Meas. Tech., 14, 1-35, https://doi.org/10.5194/amt-14-12021, 2021.

Toon, G. C., Blavier, J.-F., Sung, K., Rothman, L. S., and Gordon, I. E.: HITRAN spectroscopy evaluation using solar occultation FTIR spectra, J. Quant. Spectrosc. Ra., 182, 324-336, 2016.

UN: 2018 Demographic Yearbook, Department of Economic and Social Affairs, United Nations, New York, 2019.

Vandaele, A., Hermans, C., Simon, P., Carleer, M., Colin, R., Fally, S., Mérienne, M., Jenouvrier, A., and Coquart, B.: Measurements of the $\mathrm{NO}_{2}$ absorption cross-section from $42000 \mathrm{~cm}^{-1}$ to $10000 \mathrm{~cm}^{-1}(238-1000 \mathrm{~nm})$ at $220 \mathrm{~K}$ and $294 \mathrm{~K}$, J. Quant. Spectrosc. Ra., 59, 171-184, https://doi.org/10.1016/S00224073(97)00168-4, 1998.

Vigouroux, C., Hendrick, F., Stavrakou, T., Dils, B., De Smedt, I., Hermans, C., Merlaud, A., Scolas, F., Senten, C., Vanhaelewyn, G., Fally, S., Carleer, M., Metzger, J.-M., Müller, J.-F., Van Roozendael, M., and De Mazière, M.: Ground-based FTIR and MAX-DOAS observations of formaldehyde at Réunion Island and comparisons with satellite and model data, Atmos. Chem. Phys., 9, 9523-9544, https://doi.org/10.5194/acp-9-9523-2009, 2009.

Vigouroux, C., Bauer Aquino, C. A., Bauwens, M., Becker, C., Blumenstock, T., De Mazière, M., García, O., Grutter, M., Guarin, C., Hannigan, J., Hase, F., Jones, N., Kivi, R., Koshelev, D., Langerock, B., Lutsch, E., Makarova, M., Metzger, J.-M., Müller, J.-F., Notholt, J., Ortega, I., Palm, M., Paton-Walsh, C., Poberovskii, A., Rettinger, M., Robinson, J., Smale, D., Stavrakou, T., Stremme, W., Strong, K., Sussmann, R., Té, Y., and Toon, G.: NDACC harmonized formaldehyde time series from 21 FTIR stations covering a wide range of column abundances, Atmos. Meas. Tech., 11, 5049-5073, https://doi.org/10.5194/amt-11-5049-2018, 2018.

Wagner, T., Beirle, S., and Deutschmann, T.: Three-dimensional simulation of the Ring effect in observations of scattered sun light using Monte Carlo radiative transfer models, Atmos. Meas. Tech., 2, 113-124, https://doi.org/10.5194/amt-2113-2009, 2009. 
Wang, Z., Shao, M., Chen, L., Tao, M., Zhong, L., Chen, D., Fan, M., Wang, Y., and Wang, X.: Space view of the decadal variation for typical air pollutants in the Pearl River Delta (PRD) region in China, Front. Env. Sci. Eng., Higher Education Press and Springer-Verlag Berlin Heidelberg, 10, 9, https://doi.org/10.1007/s11783-016-0853-y, 2016.

Wittrock, F., Richter, A., Oetjen, H., Burrows, J. P., Kanakidou, M., Myriokefalitakis, S., Volkamer, R., Beirle, S., Platt, U., and Wagner, T.: Simultaneous global observations of glyoxal and formaldehyde from space, Geophys. Res. Lett., 33, L16804, https://doi.org/10.1029/2006GL026310, 2006.

Zhang, C., Liu, C., Hu, Q., Cai, Z., Su, W., Xia, C., Zhu, Y., Wang, S., and Liu, J.: Satellite UV-Vis spectroscopy: implications for air quality trends and their driving forces in China during 2005-2017, Light: Science \& Applications, 8, 100, https://doi.org/10.1038/s41377-019-0210-6, 2019.
Zhu, S., Li, X., Yu, C., Wang, H., Wang, Y., and Miao, J.: Spatiotemporal Variations in Satellite-Based Formaldehyde (HCHO) in the Beijing-Tianjin-Hebei Region in China from 2005 to 2015, Atmosphere, 9, 5, https://doi.org/10.3390/atmos9010005, 2018.

Zoogman, P., Liu, X., Suleiman, R., Pennington, W., Flittner, D., AlSaadi, J., Hilton, B., Nicks, D., Newchurch, M., Carr, J., Janz, S., Andraschko, M., Arola, A., Baker, B., Canova, B., Chan Miller, C., Cohen, R., Davis, J., Dussault, M., Edwards, D., Fishman, J., Ghulam, A., González Abad, G., Grutter, M., Herman, J., Houck, J., Jacob, D., Joiner, J., Kerridge, B., Kim, J., Krotkov, N., Lamsal, L., Li, C., Lindfors, A., Martin, R., McElroy, C., McLinden, C., Natraj, V., Neil, D., Nowlan, C., O'Sullivan, E., Palmer, P., Pierce, R., Pippin, M., Saiz-Lopez, A., Spurr, R., Szykman, J., Torres, O., Veefkind, J., Veihelmann, B., Wang, H., Wang, J., and Chance, K.: Tropospheric emissions: Monitoring of pollution (TEMPO), J. Quant. Spectrosc. Ra., 186, 17-39, 2017. 